\author{
FARKAS, ZOLTÁN PHD, HABIL
}

farkas.zo52@gmail.com

szociologist

\title{
Social Positions and Social Statuses on a Shop Floor
}

An Empirical Illustration of the Theoretical Conception

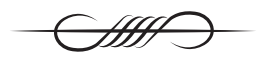

\begin{abstract}
In this paper, I illustrate the institutional (and relational) sociological conception of social position and social status by a brief description of a case study. I analyse the social positions and the social statuses of the workers, as well as the determinedness of social statuses by the given social positions on a machine industrial shop floor. First, I outline the interests and social powers of the workers. Next, I map the social positions of the workers, that is, I outline the social structure of the shop floor. Then I deal with the social statuses and the social determinedness of social statuses, and finally I briefly touch upon the performance orientations of the workers.
\end{abstract} Keywords

social position, social status, types of social position, determinedness of social status, shop floor relations

DOI 10.14232/belv.2021.3.1

https://doi.org/10.14232/belv.2021.3.1

Cikkre való hivatkozás / How to cite this article:

FARKAS, ZOLTÁN (2021): Social Positions and Social Statuses on a Shop - Floor An Empirical Illustration of the Theoretical Conception. Belvedere Meridionale vol. 33. no. 3. 5-38. pp

ISSN 1419-0222 (print)

ISSN 2064-5929 (online, pdf)

(Creative Commons) Nevezd meg! - Így add tovább! 4.0 (CC BY-SA 4.0)

(Creative Commons) Attribution-ShareAlike 4.0 International (CC BY-SA 4.0)

www.belvedere-meridionale.hu 


\section{INTRODUCTION}

In a theoretical article entitled Social Position and Social Status: An Institutional and Relational Sociological Conception, I deal with the concepts of social position and social status, the types of social position, as well as the determinedness of social statuses by the given positions (FARKAS 2020). In this paper, I will illustrate the conception of social position and social status as discussed in the mentioned article by a brief description of a case study. I will analyse the social positions and the social statuses of the workers, as well as the determinedness of social statuses by the given social positions on a machine industrial shop floor. I would like to point out that a satisfactory understanding of this paper requires knowledge of the theoretical article. In the following few paragraphs, I summarize very briefly the main concepts and connections discussed in it.

In the theoretical article, I introduced two different concepts, labelled as social position and social status. In my conception, social position means the position of the given individual (or group) in the system of social relations, which includes partly the position in the system of interest relations, partly the position in the system of social power relations. I defined the concept of social status in connection with the concept of the degree of interest realization. Social status is the degree of interest realization in the given social group or social sphere of life regarding all of the interests of the individual as compared to the degree of interest realization of others. I pointed out that the degree of interest realization and the social status are basically determined by the social position of the given individual or group, in other words by his/her or its positional social power given in his/her or its social position.

In real life, social positions can be rather complex, but by typifying social positions, we can point out their main features as well as certain regularities of how social relations work. Taking the authority position as a reference position, I typified the various social positions from the point of view of the two components of social positions: the power relations with those in the authority position and the interest relations with them (see Table 1). I distinguished authority position, exposed position, restricted position, patronized position, supported position, (strong, medial and weak) tolerated positions and rival position as the main types. I emphasized, that determined by the typical social positions, the individuals in a given social position realize their interests to a certain extent and achieve a better or worse social status.

\begin{tabular}{|c|c|c|c|c|}
\hline \multirow{2}{*}{$\begin{array}{l}\text { Power relations } \\
\text { with those in } \\
\text { the authority } \\
\text { position }\end{array}$} & \multicolumn{3}{|c|}{$\begin{array}{l}\text { Interest relations } \\
\text { with those in the authority position }\end{array}$} & \multirow{2}{*}{$\begin{array}{l}\text { Neutral inter- } \\
\text { est relation }\end{array}$} \\
\hline & $\begin{array}{l}\text { Interest identity } \\
\text { or coincidence }\end{array}$ & $\begin{array}{c}\text { Ambivalent } \\
\text { interest relation }\end{array}$ & $\begin{array}{l}\text { Interest } \\
\text { contrary }\end{array}$ & \\
\hline Balanced & $\begin{array}{l}\text { Authority } \\
\text { position }\end{array}$ & $\begin{array}{l}\text { Strong tolerated } \\
\text { position }\end{array}$ & $\begin{array}{c}\text { Rival } \\
\text { position }\end{array}$ & \multirow{3}{*}{$\begin{array}{l}\text { Marginal } \\
\text { positions }\end{array}$} \\
\hline $\begin{array}{l}\text { Moderately un- } \\
\text { equal }\end{array}$ & $\begin{array}{l}\text { Supported } \\
\text { position }\end{array}$ & $\begin{array}{l}\text { Medial tolerated } \\
\text { position }\end{array}$ & $\begin{array}{l}\text { Restricted } \\
\text { position }\end{array}$ & \\
\hline Largely unequal & $\begin{array}{l}\text { Patronized } \\
\text { position }\end{array}$ & $\begin{array}{l}\text { Weak tolerated } \\
\text { position }\end{array}$ & $\begin{array}{l}\text { Exposed } \\
\text { position }\end{array}$ & \\
\hline $\begin{array}{l}\text { Neutral power } \\
\text { relation }\end{array}$ & \multicolumn{3}{|c|}{ Parallel positions } & $\begin{array}{l}\text { Neutral posi- } \\
\text { tion }\end{array}$ \\
\hline
\end{tabular}


Finally, I pointed out, that at the abstract level of a theory, we constitute ideal-typical concepts, and, by using such concepts, we formulate connections. Nevertheless, at the concessionary level of the theory and in empirical research into social positions, we can consider the complexity of real social relations to a more significant extent, especially (1) possibly the relative undeterminedness of the authority position, (2) possibly the existence of rival position, and (3) the social relations of the given individual or individuals in relation to those outside the authority position.

While discussing social positions and statuses, to a certain extent, I will also deal with the social structure and the stratification of the given shop floor. However, in the present paper I do not deal with the structure and stratification conception that is in close connection with the conception of social position and social status as discussed in the theoretical article (about this in short see: FARKAS 2019. 3-22.). Here, I only point out very briefly in what sense I will use the concepts of social class and social structure, and I will try to avoid the use of the concepts concerning social stratification. In my conception, social class is the aggregate of individuals in essentially similar social positions in the given social group. Thus, we classify the individuals on the basis of their essentially similar or different social positions into the same or into different social classes. Social structure is the specific whole of the social classes making up the given social group and the typical social relations between the given classes. In another paper I outlined the social structure of the capitalist society, which, in this way, can be regarded as another empirical illustration of social positions in my conception (about this in short see: FARKAS 2019. 11-15.).

The above-mentioned research was carried out in the Machining Shop Floor of the Pump Manufacturing Factory Unit of the Diósgyőr Machine Works (Miskolc, Hungary). I did the fieldwork long before the 'regime change' (in December 1983 and in January and February 1984), in the socialist era; the examined period was the year 1983. The factory unit produced pumps ranging from small-sized diving pumps to large-sized agricultural pumps. The cutting processes necessary for the production of the parts of pumps took place in the examined machining shop floor. The rough layout of the shop floor is included in Figure 1 in the appendix. It also shows that the machine park consisted of traditional cutting machines except for two numerical-control (NC) lathes. There were 80 machine operators working on the shop floor, and with the exception of five semi-skilled workers, all of them were skilled workers. Almost half of the workers were centre lathers, the other half were special lathers, revolver lathers, revolver lathe setters, NC lathers, horizontal lathers, millers, grinders, radial drillers and slotters. The shop floor management was composed of the head of shop floor and five foremen. ${ }^{1}$

The theoretical conception concerning social positions and statuses discussed in the theoretical article started to evolve in the 1980s while I was doing some empirical sociological research on the shop floors. Although, at that time, I worked out the theory of institutional sociology, which this conception fits into, only in its main concepts and the main connections between these concepts, in the research in question I had already carried out the data collection and analysis on the basis of this conception. As the sociologist of the machine factory, I examined

It is worth mentioning that Miklós Haraszti's book entitled A Worker in a Worker's State was based on the experience he gained on a similar shop floor in socialist Hungary (HARAszTI 1977). Besides, Michael Burawoy carried out some research between 1984 and 1987 in Hungary, and the machining shop floor in the 'Bánki' machine factory, where he did his research in 1984, was very similar to the shop floor I did my research in (BURAwOY - LuKÁcs 1992. 35-80.). 
the given shop floor in various ways. I conducted a questionnaire-based interview with all the workers available (72 persons) while I completed the closed-ended questions with open-ended questions and a detailed discussion of certain issues. I also conducted in-depth interviews with some selected workers, accompanied some workers and foremen as a non-participant observer, and processed official documents and data. Next, I will very briefly analyse the social positions and statuses on the given shop floor. I base my analysis on the original data analysis (then still on a large computer with individual programs) using only a small part of the data available. By briefly presenting a part of the results of my research, I aim to illustrate the concepts and connections discussed in the theoretical article rather than review the given shop floor and the research methods I used. Therefore, I will not review the operationalization of the theoretical concepts, the concessions made in the course of the operationalization and the empirical research methods in detail.

Although it was several decades ago that I did the research, I will generally write about the shop floor in question in the present tense. First, I will outline the interests and social powers of the workers. Next, I will map the social positions of the workers, that is, I will outline the social structure of the shop floor. Then I will deal with the social statuses and the social determinedness of social statuses, and finally I will briefly touch upon the performance orientations of the workers.

\section{INTERESTS AND SOCIAL POWERS ON THE SHOP FLOOR}

\section{Components of interests}

As mentioned in the theoretical article, social position includes partly the position in the system of interest relations, partly the position in the system of social power relations. Thus, in order to survey the interest relations and social power relations on the shop floor, and to define the social positions, first we have to survey the interests and the social powers of the workers.

In my conception, from the point of view of motivation, the conduct of the workers on the shop floor is basically determined by their interests, that is, they are motivated by their realizable and known interests. If earnings refer to money earned from work on the shop floor, earnings constitute the main social goods that their interests are directed to. Thus, I will call the shop floor interests of the workers earnings interest. Earnings interest is the network of action possibilities created by institutions that may lead to the highest possible earnings available in the validity scope of the given institutions with an acceptable expenditure. In my conception, interests are factual environmental entities existing independently of the awareness of individuals and their conduct determined by the given interests. In another paper, I gave a very detailed analysis of the earnings interests of the workers on the given shop floor, and I also pointed out the social institutions and material-technical circumstances that create the components of the interests, that is, the action possibilities constituting the interests (FARKAS 2011). However, for reasons of space, here I only point out very briefly the main components of interests.

In the direct production shop floors of the Diósgyőr Machine Works, among the workers involved in direct production, payment by results was applied everywhere, while on the machining shop floors, individual payment by results was used. Thus, on the machining shop floor, the 
subject of the research, the operators of cutting machines were also paid individually by results. According to the system of individual payment by results applied on the shop floor, the basic component of earnings is the (mathematical) product of the personal wage - specified for each worker as an individual, concerning one hour of norm time - and the performance of the worker measured in norm time. ${ }^{2}$ The basic wage is supplemented by different allowances due to various titles, as well as by payment for non-working hours.

In Figure 2, I demonstrate that the components of earnings interests on the given shop floor can be interpreted at three levels from the point of view that the components at the same level are basically created or determined by the social institutions that can be assigned to the given level. The first level includes the general feature of the earnings interest that the earnings interest is made up of the action possibilities of optimizing the earnings and expenditures. At this level, the interests of the workers are determined by certain legal institutions and institutions or agreements within the families. The second level includes the components concerning wage factors that are mainly created by the institutions of the incentive system and the performance account of the firm. At this level, the earnings interests of the workers are mainly made up of the maximization of their personal wage, and the optimization of their performance percentage and their additional work. What earnings the workers earn at what expenditure of labour on the given shop floor depends mainly on what personal wage they have, what performance percentage they have achieved, and how much additional work they do. Consequently, these factors or rather the action possibilities that are in connection with them are also at the centre of the earnings interests of the workers.

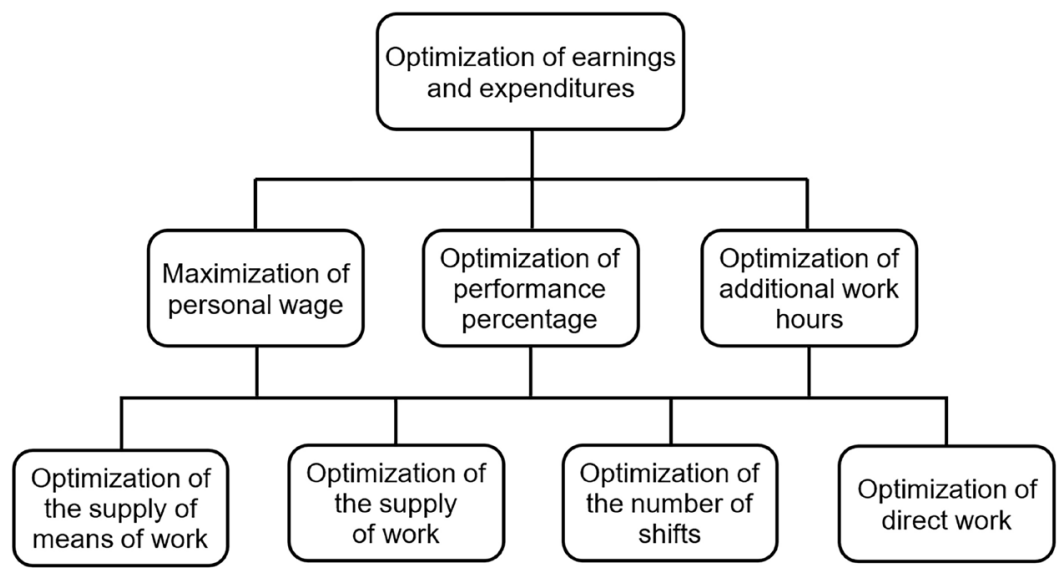

Figure 2. Components of earnings interests

Personal wage is the wage for one hour of work according to the accomplished norm time, which, in this way, significantly affects the worker's earnings. When determining the personal wage of a worker, the managers take the qualifications and work experience of the worker into consideration, but also evaluate the worker's behaviour at work in a discretionary way.

2 The norm time is the amount of time necessary to carry out a specific work or task according to the technological instructions. 
Performance percentage shows how long it took the worker to complete the task compared to the period of time specified for the given task, the so-called norm time. Thus, as an example, if it takes a worker 50 minutes to do one hour's work according to the norm time, he or she achieves $120 \%$ performance; if, on the other hand, it takes him or her 80 minutes to do one hour's work, he or she will only achieve $75 \%$ performance. There are two forms of work outside the normal working hours, i.e., additional work on the given shop floor. One of them is the traditional overtime, which is a simple extension of working hours; but the wage earned on the basis of the performance during overtime is supplemented by an overtime allowance. The other is work in an internal subcontracting form, work done in the frame of the economic work partnership (GMK). There are six workers who are members of the economic work partnership established on the machining shop floor and they do additional work in the frame of this partnership.

The third level of the components of interests includes the components concerning means of work, work tasks and doing work, which are mostly created by the institutions of labour division, workplace supply, quality control and the institutions of the so-called 'quasi-ownership'. The main components of earnings interests at this level are as follows: optimization of the supply with means of work, optimization of work supply and, in connection with this, loosening of norm times; and in close connection with the former issues, the optimization of the number of shifts and the optimization of direct work.

Supply of the means of work includes supply of machine, on the one hand, and supply of tools and special devices, on the other. Supplying the worker with a machine usually marks out the regular workplace (workstation) of the worker for a longer period of time. The machine and the workplace that make it possible for the worker to achieve the highest possible earnings with a specified expenditure, or where the specified earnings require the least possible expenditure, correspond to the earnings interest. In the research in question, I tried to survey which characteristics of the machines on the shop floor were significant from the above-mentioned points of view, and to what extent the individual machines corresponded to the interests of the workers (FARKAS 2011. 24-28.). However, I only point out here that it is principally important for the workers that the machine should be in a good mechanical state and the norm time of the tasks belonging to the given machine or the tasks that can be performed on the given machine should be comparatively easy. At the same time, the machines that can be found on the shop floor are markedly different from each other from the point of view of these characteristics.

Besides the optimization of the supply of machine, within the interest component concerning means of work, the action possibilities making up the earnings interests are aimed at the optimization of the supply with tools and special devices. In general, we can say that the tools and special devices correspond to the interests of the workers if they are in a good state, can withstand a load larger than the load at the specified cutting speed and depth of cut, and are instantly available.

Regarding the supply of work, the higher the earnings that can be achieved with the required expenditures, or the less work expenditure the defined earnings require, the more the work tasks and workpieces correspond to the earnings interest. The most important issue of the optimization of work supply is differentiation between 'good jobs' and 'bad jobs' and obtaining the socalled 'good jobs'. The 'good' task and workpiece mean that the norm time of the given work is easy, while the norm time of the so-called 'bad job' is comparatively strict. In connection with 
this, the action possibilities making up the interests of the workers are aimed at (1) work tasks with longer piece time, i.e., tasks that contain more cutting operations and long operation time, (2) pieces of less hard materials and (3) workpieces only recently given in production; (4) the longer these tasks and workpieces provide the worker with continuous work and (5) the more they are repeated, the more they correspond to the workers' interests. Relying on objective data, I have arrived at the conclusion that, concerning the 'goodness' of tasks, there can be up to three-to-fourfold differences between the different tasks and workpieces on a given shop floor.

The component of earnings interest concerning the optimization of the number of shifts and shift-rota is closely related to the components concerning the optimization of means of work and work supply. The Machining Shop Floor usually operates in two shifts, the morning and the afternoon shift, that is, the workers usually work in one or two shifts. Occasionally, however, the management may also order a three-shift system for certain machines or for certain workers. From the point of view of the optimization of the supply with work, workpieces and means of work, it is the one (morning) shift that corresponds most to the earnings interest. Nevertheless, if the worker is not able to achieve a favourable status regarding the supply of work, workpieces and means of work, the two-shift system, or, perhaps, the three-shift system may prove to be more favourable. The advantages of working in two or three shifts are that the workers are paid a bonus of 20 percent for the afternoon shift and a bonus of 40 percent for the night shift. According to the answers given to this question, 32 percent of the workers prefer the one-shift work, 54 percent the two-shift work and 14 percent the three-shift work.

As we could see above, the interests of the workers do not concern only the direct work. However, the action possibilities of optimizing the direct work are also important components of their interests. As for the intensity of work, it is mostly continuous work, without unintentional or intentional interruptions, with appropriate rest periods, done at a constant intensity that is, in the form of action possibilities, in the interest of the workers. Besides, they act according to their own interests also in the longer term if they produce workpieces machined of the appropriate quality. However, the careful use of machines, tools and devices constitutes their interest to a medium, rather than to a large extent. From the point of view of the extent to which it pays off to take fellow-workers into consideration, the workers' interests are made up of action possibilities that include considering the probable consequences of the actions, with respect to the workers with whom the given worker has social relationships, on the one hand, and those who have considerable social powers towards the given worker, on the other hand. In the paper referred to above, I pointed out that the components of the workers' interests that concern direct work are also significantly different from the action possibilities that can be inferred from the formal norms (FARKAS 2011. 34-36.).

The main interest components in question are of different weight, especially in connection with the fact that the degree of the realization of certain components largely determines the realizability of other components. The workers, however, not only know the individual components of their interests to a satisfactory degree, but, at the level of practical rationality, they also have a clear insight into the connections between the individual components. To support this statement, I point out how the workers give importance to the main components making up their earnings interests. In the questionnaire, I asked the workers to rank the individual components from the point of view of how important they think their realization is. 


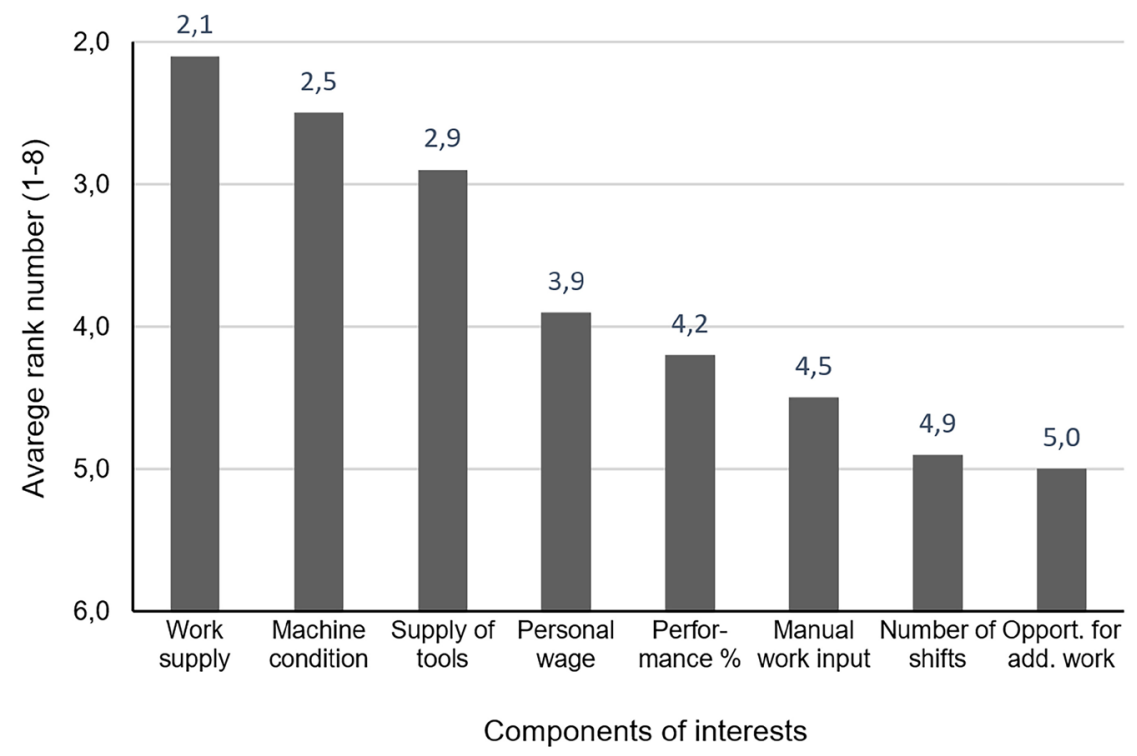

Figure 3. Rank order of the main components of earnings interests

Figure 3 shows that the workers regard the optimization of work supply, that is, the appropriate supply of work and workpieces, as well as the norm times that are favourable for them, as the most important. The next most important aspect for them is supply of the means of work, and, within this, they consider the optimization of the supply of machine more important than the supply of tools and special devices. These factors are followed by the components concerning the optimization of personal wage and performance percentage, then the component concerning the optimization of the work expenditure in the direct work. Finally, they regard the appropriate number of shifts and the possibility of additional work as the least noteworthy.

It is striking that the workers do not emphasize the importance of the interest components that I defined at the second level of earnings interests, the ones that are most closely related to earnings, but rather the components concerning tasks, workpieces and means of work, the effect of which on earnings and expenditures is far more indirect. In the present paper I do not deal with the mechanism of interest realization; I only remark here that, in the rank formed by the workers, it is crucially the actual determinedness between the individual interest components that are reflected. From the point of view of earnings interests, continuous supply with relatively 'good' works and the appropriate supply of the means of work are fundamental. These factors basically determine the realizability and efficiency of work expenditure and, in close connection with this, performance percentage and additional work. The components concerning personal wage and the number of shifts depend on other components to a lesser degree, but personal wage in itself is already an important determinant of earnings and expenditures.

In my research, I aimed to survey the expectations and attitudes of workers regarding the intensity of work, the quality of work, careful use of the means of work and consideration of fellow-workers. I tried to find the answer to the question of whether these expectations and attitudes reflect their interests or their personal and community values. I came to the conclusion that 
personal and community values, as well as community moral norms do not restrict considerably the motivating effect of earnings interests.

\section{Social powers}

According to some conceptions, social power cannot be measured since this concept includes the aspects of social reality the quantitative expression of which is not possible. In some other conceptions, social power can be measured, and to measure the intensity of social power, typically, two methods are applied in sociological research: the reputational method and the event or effect method (BARNES 1988. 8-12.). The reputational method means assessing the power of certain actors by asking other actors who they believe to be most influential in the given area of social life (D’Antonio - Erickson 1962; Fischer - SCIARINI 2015; MARgetTs 2011). This method is mainly used in the field of politics and in the research into the powers prevailing in political decision-making processes (e.g. HENRY 2011; KRIESI - AdAM - Jochum 2006). The representatives of the effect method regard the consequences attributed to the social power as the indicator of power. As an example, according to WHITMEYER (2001), the intensity of social power can be assessed by measuring the expected outcomes of the power. GolDBERG (2006) examined power relations in political alliances by observing phenomena regarded as the consequences of the powers exercised, by what he called the ethnographic method.

In the given research, I considered it important to measure social powers independently of the social phenomena that we can partly regard as the consequences of the given powers. I measured the intensity of the social powers of workers towards the shop floor managers and towards all the workers on the shop floor by asking two questions. To measure the power towards the managers of the shop floor, I asked three out of six members of the management, the head of shop floor and two foremen, the following question: 'To what extent could the individual workers help or hinder the managers in their ambition to ensure that the shop floor meets the requirements of the factory unit management if this was their intention?' To answer this question, the respondents were expected to take the previous year (1983) as a basis, and, in the course of the analysis, I took the answers of the head of shop floor and of the two foremen with equal weight into consideration, and I calculated the social power towards the managers in this way. To measure the powers between the workers, I asked the given worker the following question: 'To what extent could you help or hinder your fellow-workers in their work to achieve higher earnings if you intended to and if you set aside the probable reaction of the other party?' With the person (manager or worker) interviewed I considered all the machine workers one by one, and he or she had to rank them on a scale ranging from one (to a small extent) to five (to a very large extent) when answering the above-mentioned question.

I determined the average powers of the workers towards their fellow-workers, and then I classified the workers according to their powers towards the managers on the one hand, and according to the intensity of their average powers towards their fellow-workers on two separate scales ranging from one to five (from small powers to large powers), which I do not present here. Based on the answers to the above-mentioned questions, we can say that the powers of all of the 80 workers towards their managers were known, but only 67 workers answered the question regarding their powers towards their fellow-workers, (however, their powers towards all their fellow-workers 
were known). Nevertheless, from the point of view of determining social positions, it is an important variable; therefore, on the basis of some other information, I also assessed the average power of the workers who gave no answer to the question towards their fellow-workers. ${ }^{3}$

As I mentioned in the introduction of the theoretical article, social power is the degree of the social abilities of the given individual (or group) in which these abilities constitute the means or conditions of need satisfaction for another individual (or group) as an object. While preparing the research I assumed that the components of the social powers of the workers are mainly made up of the following social abilities: (1) scope of action at work, (2) expertise, (3) scope of action in the party or the trade union, (4) social relationship and (5) quasi-ownership on the shop floor.

The scope of action at work mostly includes the work tasks that the workers have to perform at the given workplace. Performing certain work tasks in time and of the proper quality may affect the interests of the managers to a larger extent than performing other work tasks. Consequently, the different scopes of action may constitute different degrees of power towards the managers of the shop floor. From the point of view of the fellow-workers, the scope of action may also constitute a significant social ability, especially depending on how and to what extent the scopes of action of the different workers are connected to each other in the technological process.

On shop floors where workers are paid individually by results, one of the most important social abilities is the expertise necessary for performing the work tasks falling into the scope of action of the worker. Besides expertise, the indicator I applied also includes the effort the worker makes during his or her normal working hours. Expertise can be regarded as ability and social ability; effort made at work relies on motives rather than abilities. Originally, I used the more complex indicator because I required it for another purpose (later I also measured expertise itself but in this context I still used the former indicator). I measured expertise and effort on the basis of the evaluation of two foremen; I asked the managers to evaluate the workers according to their expertise and the effort they put in during their normal working hours. Finally, I classified the workers into four categories: very good (18 men), relatively good (29 men), medium (20 men) and satisfactory (23 men) in respect of expertise and effort.

On the shop floor, 10 workers $(12.5 \%$ ) have relatively significant party or trade union (as well as youth organization, i.e. KISZ) scope of action, which means a formal entitlement to influence managerial decisions affecting the interests of workers. Eight out of the ten workers in question are trade union officers (shop stewards, members of the committee of the trade union), one is a party group officer and one the secretary of the youth organization (KISZ).

I measured social relationships with the number of the relationships (mutual choices) revealed by a network research method. As for relationships with workers and shop floor managers, 34 workers (43\%) have no relationships at all, 29 workers $(36 \%)$ have relationships with one or two people, and another 17 workers $(21 \%)$ have social relationships with three, four or five people on the examined shop floor. ${ }^{4}$

Three workers evaded the question saying that they do not have considerable influence on their fellow-workers, therefore I classified them into the group of workers with small average power. I determined the average powers of the other workers who gave no answer towards their fellow-workers (10 people) considering partly their average power towards the management, and partly the social abilities most important from this aspect, namely, expertise (and effort) and the scope of action at work. These factors were known in the case of all the workers.

4 There were nine workers who did not take part in the network survey. I determined the probable number of their relationships on the basis of the unilateral choices where they were named. 
Contrary to the official norms, the managers of the shop floor and the workers in advantageous positions have shaped what I call the institution of quasi-ownership, which means that, within certain limits, certain workers may take possession of some means of work, workpieces and work tasks. Of course, within their scope of action, the workers can mostly dispose of the means of work and workpieces; by quasi-ownership I mean disposal beyond this. Firstly, regarding the machines, it means that the worker, as the 'owner' of his or her machine, cannot be transferred to another machine against his or her will. Secondly, the owner-workers can develop their own sets of tools and devices, which they are relatively free to dispose of. Thirdly, some workers may also take possession of some workpieces or work tasks. In this way, the workers can obtain work tasks or workpieces that are in their quasi-ownership and that are, from the point of view of earnings interests, favourable for them, disregarding the individual decisions of foremen and dispatchers. The worker may request that these workpieces be directed to his or her machine, without it being transported first to the storeroom of the shop floor; and to start the work he or she does not need to ask for the approval of the foreman, either.

\begin{tabular}{|c|c|c|c|c|c|}
\hline \multirow{2}{*}{ Social power } & \multicolumn{5}{|c|}{ Social abilities } \\
\cline { 2 - 6 } & $\begin{array}{c}\text { Scope of } \\
\text { action at } \\
\text { work }\end{array}$ & $\begin{array}{c}\text { Expertise } \\
\text { (end effort) }\end{array}$ & $\begin{array}{c}\text { Scope of ac- } \\
\text { tion in party } \\
\text { or trade union }\end{array}$ & $\begin{array}{c}\text { Social } \\
\text { relationships }\end{array}$ & $\begin{array}{c}\text { Quasi- } \\
\text { ownership } \\
\text { on shop floor }\end{array}$ \\
\hline $\begin{array}{c}\text { Power towards } \\
\text { managers }\end{array}$ & 0.45 & 0.80 & 0.43 & 0.61 & 0.83 \\
\hline $\begin{array}{c}\text { Power towards } \\
\text { workers }\end{array}$ & 0.53 & 0.65 & 0.35 & 0.46 & 0.46 \\
\hline
\end{tabular}

Table 2. Correlation of the intensity of social powers with the main social abilities

We may gain some impression about the importance of the above-mentioned social abilities if we have a look at the correlation coefficients between these factors and the intensity of social powers. Table 2 shows that the intensity of the powers towards managers is in very close connection with the quasi-ownership and expertise (and effort). Social relationships correlate with the powers towards the managers to a lesser degree, and the scope of action at work and in party or trade union comparatively the least. Expertise (and effort), then the scope of action at work are relatively in the closest connection with the intensity of the social powers towards the workers. Social relationships and quasi-ownership correlate less with the powers towards the workers, and scope of action in party or trade union the least.

As is well-known, simple correlation coefficients do not properly express how important the social abilities in question are by themselves, relatively independently of each other, as the components of social powers are. Therefore, I tried to demonstrate by path analysis to what extent these social abilities constitute the components of the powers of the workers towards the managers of the shop floor, on the one hand, and towards their fellow workers, on the other. In this respect, I deal with the powers towards the managers in more detail, because - as we will see below - these powers are more significant from the point of view of the extent to which the workers realize their interests, and what social status they achieve. 


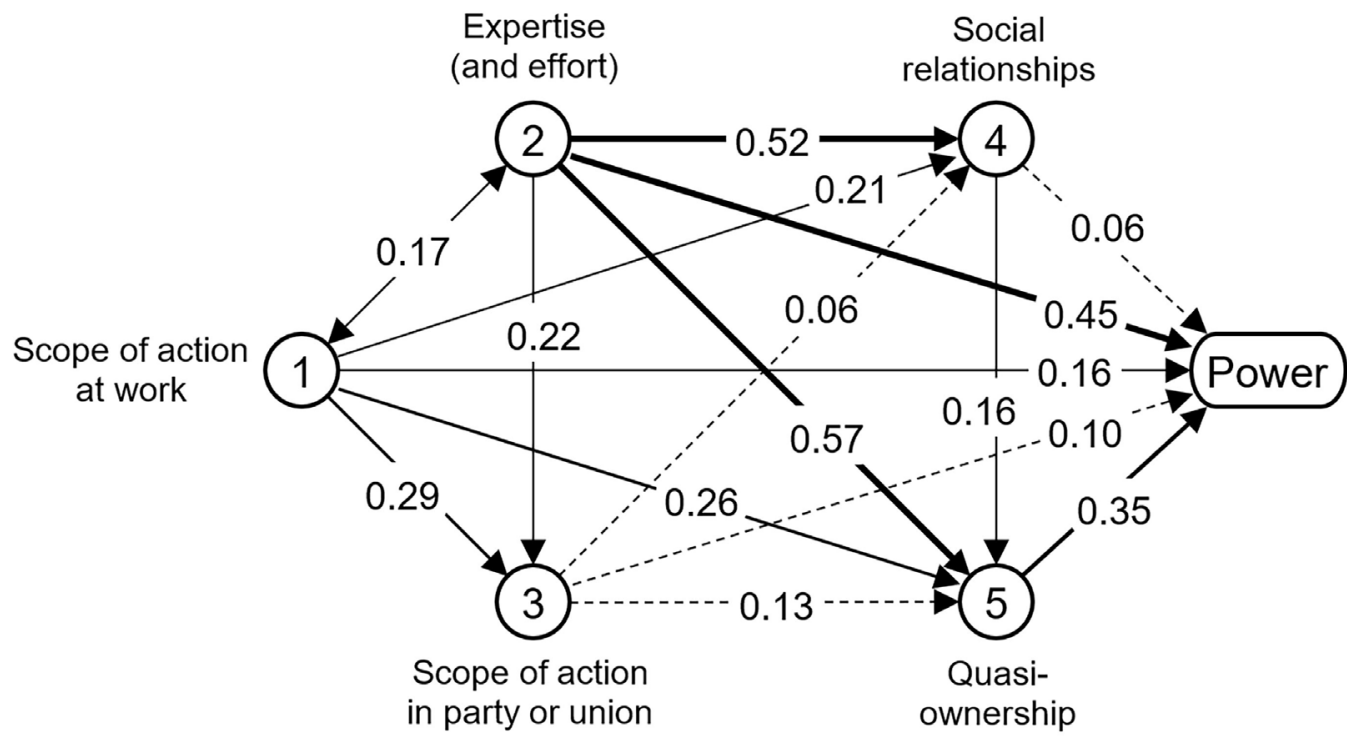

Figure 4. Representation of the components of powers towards the managers by path analysis

Figure 4 shows the connections between the social abilities under review, as well as between these abilities and the intensity of power towards the managers. The arrows represent pure (or direct) effects - with directions I as the researcher assumed in advance - in the form of path coefficients, except the simple correlation coefficient between the scope of action at work and expertise (and effort). According to the figure in question, it is mainly expertise (and effort) and the quasi-ownership within the shop floor, by themselves and independently of other social abilities, that constitute the social powers towards the managers. Compared with these abilities, directly, the scope of action at work has a much smaller significance, but, in the longer term, the scope of action at work also has an effect on other social abilities. Independently of other social abilities, scope of action in party or trade union and social relationships have a rather small significance. The social abilities in question constitute 81 percent of the social powers of the workers towards the managers.

I do not analyse the components of the powers towards the workers, I only note that, according to the data, the social abilities under review amount only to nearly 58 percent of the powers towards the workers. This less close connection can mainly be explained by the fact that the powers between the workers are considerably differentiated depending on whether the given workers work on similar or different kinds of machines and how these machines are connected to each other in the technological process, or whether they happen to work on the same machine. Consequently, some of the worker's social ability towards some of his or her fellow-workers may be significant, whereas towards others it may be irrelevant. 
As mentioned above, I determined the powers of workers towards the managers and their average powers towards their fellow-workers. Taking the powers towards the managers and the average powers towards the workers with the same weight into consideration, I determined the general powers of the particular workers, and measured them on a scale ranging from one (small power) to five (large power). However, I will correct general powers below, from the point of view of mapping social positions, and outlining the social structure, attributing greater importance to the powers towards the managers.

So far, within the social power relations between the workers and the managers, I have only discussed the powers of the workers towards the managers. Regarding the power of the managers, we can assume that the head of the shop floor and the foremen have large powers towards the workers, and they have authority over the majority of the workers. Their social powers are decisively made up of their managerial scope of action, but partly, also, of their social relationships. The scope of the power of the managers includes employing workers, determining their scope of activities, job title and personal wage on the one hand, leading and controlling the everyday activity of the workers on the other.

\section{SOCIAL POSITIONS AND SOCIAL STRUCTURE}

As seen in the theoretical article, while highlighting the authority position as a reference position, we determine the typical social positions taking the social relations to those in the authority position into consideration. However, during the empirical survey of the social position of individuals, to a certain extent, we may also take their social relations to other individuals and groups with relatively significant powers into consideration. Although we are interested in workers, while determining the social positions of the workers and outlining the social structure of the shop floor, we have to keep in mind that the managers of the shop floor (the head of shop floor and the foremen) have considerable powers towards the workers, and they have authority over the majority of the workers. Therefore, in the research in question, I also aimed to survey the social relations of the workers to the managers.

As mentioned above, while taking the powers towards the managers and the average powers towards the workers with the same weight into consideration, I determined the general powers of the particular workers. However, I corrected the general powers from the point of view of mapping social positions, and outlining the social structure, attributing greater importance to the powers towards the managers. Finally, according to their corrected general powers, I placed the workers into three categories. By the correction of the general power I mean that I also took the powers towards the management into consideration separately when categorizing according to powers. Namely, according to the data, independently of the powers towards the managers, the powers towards the workers have no significant effect on the degree of interest realization and social (earnings) status. Regarding the connections between the three factors in question we can state that the correlation coefficient between the power towards the managers and the average power towards the workers is 0.53 ; the partial correlation coefficient between the power towards the managers and the social (earnings) status (to be discussed below) is 0.81 ; whereas the partial correlation coefficient between the average power towards the workers and the social (earnings) status is only 0.08 . 
According to the corrected general powers, the workers whose general power reaches or exceeds 3.35, and/or their power towards the managers reaches or exceeds 4.00 have large corrected general power. The workers whose general power falls between 2.61 and 3.34, and/or their power towards the managers falls between 3,50 and 3,99 have medium corrected power. The workers whose general power is less than 2.61 and their powers towards the managers is less than 3.50 have small corrected power. In this way, 20 workers $(25 \%)$ have large corrected general power, 23 workers $(29 \%)$ have medium power and 37 workers $(46 \%)$ have small power. Thus, the categories according to the corrected general powers decisively express the power relations towards the managers of the shop floor, but partially they also express the power relations between the workers. ${ }^{5}$

In principle, the other aspect of typifying is constituted by the interest relations to those having authority, distinguishing, firstly, interest identity and interest coincidence, secondly, ambivalent interest relations and, thirdly, interest contrary. However, in the course of classification according to the interest relations, in the given research I not only took the interest relations to the members of the authority class into consideration, but also, the interest relations to the largely powerful workers in general and, in the case of the workers with small power, to the workers in the supported position (who have medium corrected power).

I defined the interest relations within the shop floor in the following three ways, regarding the managers on the one hand, and the fellow-workers on the other. Firstly, I surveyed the social relationships within the shop floor. I had assumed, namely, that social relationships indicate that the workers, as well as the workers and managers who are in relationship with each other conciliate their interests to a considerable extent, so their interests are largely identical. Secondly, I attempted to survey the interest relations between the workers and the managers partly with a question that I asked the head of shop floor and two foremen. I assumed that the interest relations between the workers and the managers are largely reflected by the extent to which the opinions of the managers and the opinions of the workers assumed by the managers are similar or different regarding the issues considerably affecting the interests of the workers (I measured the similarities or differences of opinions on a scale ranging from 1 to 5, where the full agreement is indicated by 5). ${ }^{6}$ Thirdly, I determined the interest relations between the workers partly by considering the interconnection or separation of means of work, work tasks and work accounts.

As we have seen in the theoretical article, the reference point of typifying social positions is, in principle, the individual or group who has authority and is in the authority position. Thus in the first place, we have to circumscribe the individuals in the authority position. If there are several individuals in the authority position, they are bound together by social relationships; these individuals form a social union or, considered at a concessionary level, a cohesive social network. Since - as I have mentioned above - it is probable that it is mainly the managers who

By excluding the effect of the other factor (powers towards the workers or the managers), the partial correlation coefficient between the powers towards the managers and the corrected general powers is 0.72 , whereas the partial correlation coefficient between the average powers towards the workers and the corrected general powers is 0.24 .

6 The question was as follows: 'To what extent would you find it acceptable if things related to work and incentives on the shop floor would change as the individual workers would presumably like it?' The manager questioned evaluated all the workers one by one with regard to the mentioned question. 
are in the authority position, I surveyed the social relationships between the workers, and between the managers, as well as between the workers and managers. ${ }^{7}$

The social relationships (mutual choices) on the shop floor are shown by Figure 5 in the appendix, according to which four out of the six managers form a solid clique, which I call the core of the management. Of all the workers having large social power I classified those into the authority social class who are members of the cohesive social network (subgroup) which includes also the four managers of the shop floor and who, in the above-mentioned figure, can be found within the section of the authority class. Besides the fact that they have large social power, these workers are linked to the network of the workers having large power and the core of the management with at least two social relationships (mutual choices). Thus, I classified 7 workers, nearly $9 \%$ of the workers into the authority social class. ${ }^{8}$ I have to remark that, from the above-mentioned aspect, I classified two workers (worker 2 and worker 15) into the category in question with some concession. Namely, according to the network diagram, these two workers have no visible social relationships with the workers in the authority position and the core of the management. However, in fact, they presumably have some relationships, since four or five persons from this circle chose them unilaterally and some other information also proved the existence of these relationships. ${ }^{9}$

Within the circle of the workers with large (corrected general) power, I classified the workers who do not belong to the authority class, into the strong tolerated social class. According to the aspects of interest relations discussed in the paragraph below, two workers (worker 28 and worker 29) would be in a rival social position, thus these workers should have been classified into the rival social class. However, the rival class would only have consisted of these two workers, so - to avoid distinguishing such a small social class - I also classified them into the strong tolerated class.

Taking only the workers with medium or small power into consideration, I classified the workers into the different categories by interest relations according to the following aspects. I

\footnotetext{
The question to the workers to survey the relationships between them was as follows: 'If, under the present circumstances, you were to be entrusted with the task of assembling the worker staff of the shop floor, who would you most like to include as fellow workers in the staff? You may choose any number of persons from among the workers of the shop floor who receive a payment by results.' Apart from the managers of the shop floor, I also involved other managers of the factory unit in the survey of social relationships, but in the present paper I do not deal with managers outside the shop floor. The question to the workers to survey the relationships of workers with their managers was as follows: 'If there were some changes made in the management of the factory unit and the shop floor, under whose direction would you most like to work from among the current managers? You may name any number of persons ranging from the head of the factory unit to the foremen. The question to be answered by the head of the shop floor and the five foremen was aimed to survey the relationships of the workers with the managers and it was the same as the first question to be answered by the workers (without the words 'as fellow workers'). In order to survey the relationships between the managers, the following question was asked (however, this question is of any interest only from the point of view of the survey of the relationships between the managers of the shop floor): 'If there were some changes made in the management of the shop floor and the factory unit, who of the present managers would you most like to continue working with? You may name any number of persons from those in managerial positions at present, including group leaders, foremen, heads of department, heads of shop floor, technical managers and the head of the factory unit.'

8 Together with the managers constituting the core of the management, workers 1, 2, 3, 15, 19, 20 and 25 compose the authority social class.

9 Worker 2 did not take part in the network survey, but he was chosen by five people from the core of the management and the circle of the workers in authority position. Worker 15 took part in the network survey and he had no visible relationships with the core of the management and the workers in authority position, but he was chosen by four persons from this circle.
} 
classified the workers who satisfy at least one of the following two requirements into the category of identity and/or coincidence interest relations. (1) From the point of view of the managers: the value of the assessment of agreement or disagreement is at least $3.75 \mathrm{and} /$ or the worker has some social relationship with the core of the management. (2) From the point of view of the workers: joint work load and accounts with a worker having large power, or, in the case of a worker with small power, with a worker in supported position, and/or social relationship with a worker in authority position, or some close family relationship with a worker with large power (e.g. wife, child, son-in-law). ${ }^{10}$

I classified the workers who satisfy at least one of the following two requirements into the category of ambivalent interest relations. (1) From the point of view of the managers: the value of the assessment of agreement or disagreement falls between 3.01 and 3.74 and the worker has no social relationship with any member of the core of the management. (2) From the point of view of the workers: joint means of work and work tasks (the same machine, jointly used tools and special devices, and typically continuing the work started by the other worker in the previous shift), but no joint accounts with a worker having large power as a shift-mate (without a social or family relationship mentioned in the former category).

I classified the workers who satisfy both of the following two requirements into the category of contrary interest relations: (1) From the point of view of the managers: the value of the assessment of agreement or disagreement is not more than 3.00 and the worker has no social relationship with any member of the core of the management; (2) From the point of view of the workers: the worker works on his or her machine on his/her own or with a worker (as a shift-mate) with no large power and he or she has separate accounts (without a social or family relationship mentioned in the former categories).

\begin{tabular}{|c|c|c|c|}
\hline \multirow{2}{*}{$\begin{array}{c}\text { Power } \\
\text { relations with } \\
\text { those in the } \\
\text { authority } \\
\text { position }\end{array}$} & \multicolumn{3}{|c|}{$\begin{array}{c}\text { Interest relations } \\
\text { with those in the authority position }\end{array}$} \\
\cline { 2 - 4 } & $\begin{array}{c}\text { Interest identity } \\
\text { or coincidence } \\
\mathbf{2 7}(33.8 \%)\end{array}$ & $\begin{array}{c}\text { Ambivalent } \\
\text { interest relation } \\
\mathbf{3 2}(40.0 \%)\end{array}$ & $\begin{array}{c}\text { Interest } \\
\text { contrary } \\
\mathbf{2 1}(26.2 \%)\end{array}$ \\
\hline Large power & Authority & Strong tolerated & Rival \\
$\mathbf{2 0}(25.0 \%)$ & $\mathbf{7}(8.8 \%)$ & $\mathbf{1 3}(16.2 \%)$ & - \\
\hline Medium power & Supported & $\begin{array}{c}\text { Medial } \\
\text { tolerated }\end{array}$ & Restricted \\
$\mathbf{2 3}(28.8 \%)$ & $\mathbf{8}(10.0 \%)$ & $\mathbf{1 1}(13.8 \%)$ & $\mathbf{4}(5.0 \%)$ \\
\hline Small power & Patronized & Weak tolerated & Exposed \\
$\mathbf{3 7}(46.2 \%$ & $\mathbf{1 2}(15.0 \%)$ & $\mathbf{8}(10.0 \%)$ & $\mathbf{1 7}(21.2 \%)$ \\
\hline
\end{tabular}

Table 3. Distribution of workers according to social positions or the social structure of the shop floor

10 To my knowledge, none of the workers had any close family relationship with the managers of the shop floor or the upper managers. 
Thus, in line with the above-mentioned criteria, I classified the workers into the different social positions and the different social classes according to the social power relations and interest relations. As we can see in Table 3, 20 workers (25\%) have large social power; among them 7 workers (nearly 9\%) are in authority position, i.e. they constitute the authority class, along with the four managers composing the core of the management. 13 workers (nearly 16\%) are in strong tolerated position and they constitute the strong tolerated class. 23 workers (nearly 29\%) have medium social power; among them 8 workers (10\%) are in supported position and in the supported class; 11 workers (nearly 14\%) are in medial tolerated position and 4 workers (5\%) are in restricted position and they constitute the medial tolerated class and the restricted class. 37 workers (nearly 46\%) have small social power; among them 12 workers (15\%) are in patronized position and they constitute the patronized class, 8 workers $(10 \%)$ are in weak tolerated position and constitute the weak tolerated class, and 17 workers (nearly $21 \%$ ) are in exposed position and constitute the exposed class. It would be worth analysing the composition of the social classes according to certain aspects (practical experience, social relationships, expertise and effort, scope of activity, party or trade union function, family-financial position, etc.), but, for reasons of space, I do not deal with this in the present paper.

As seen in the theoretical article, from the point of view of social inequalities, different social positions can also be similar, that is, from the aspect of what social statuses they make it feasibly possible to achieve, since the social status is basically determined by the inequality aspect of social position, that is, by the positional social power inherent in the social position of the given individual or group. By social stratum position I mean the inequality aspect of social position, that is, what degree of positional social power the given individual or group has. Thus, in principle, we can find more unambiguous inequalities between the different stratum positions than between certain social positions (and social classes). In the given research, from the above-mentioned aspect, I distinguished very advantageous (18 workers), relatively advantageous (21 workers), relatively disadvantageous (24 workers) and very disadvantageous (17 workers) positions. However, in the present paper, - for reasons of space - I do not deal with social stratum positions. I analyse the distribution of the degree of interest realization and social status according to the social position rather than the social stratum position, since, in this way, I can highlight the similarities and differences between the different social positions from the point of view of inequalities.

\section{SOCIAL STATUSES AND PERFORMANCE ORIENTATIONS}

\section{Social determinedness of social (earnings) status}

As mentioned above, the action possibilities constituting the earnings interest are aimed at the joint optimization of earnings and expenditures. It is not only the amount of earnings that is important for the workers, but also the efficiency of work expenditure, that is, how much they can earn through one unit of expenditure (HÉTHY - MaKó 1978. 117-118.; HILL 1986. 14.). The efficiency of work expenditure is expressed relatively well by earnings for one working hour, which I will call the hourly earnings. Figure 6 illustrates the distribution of the monthly average 
earnings and hourly earnings of the individual workers. The analysis of the earnings and their components are based on the monthly (in the case of hourly earnings, the hourly) averages of the data for the whole of the year 1983 provided by the company's wage registration.

We can see that there is a very tight connection between earnings and hourly earnings and that the earnings are very differentiated; the difference between the lowest and the highest earnings is nearly tenfold. However, such great differences in earnings were not exceptional, they were rather usual in the period under review in the machining shop floors of the Diósgyör Machine Works.

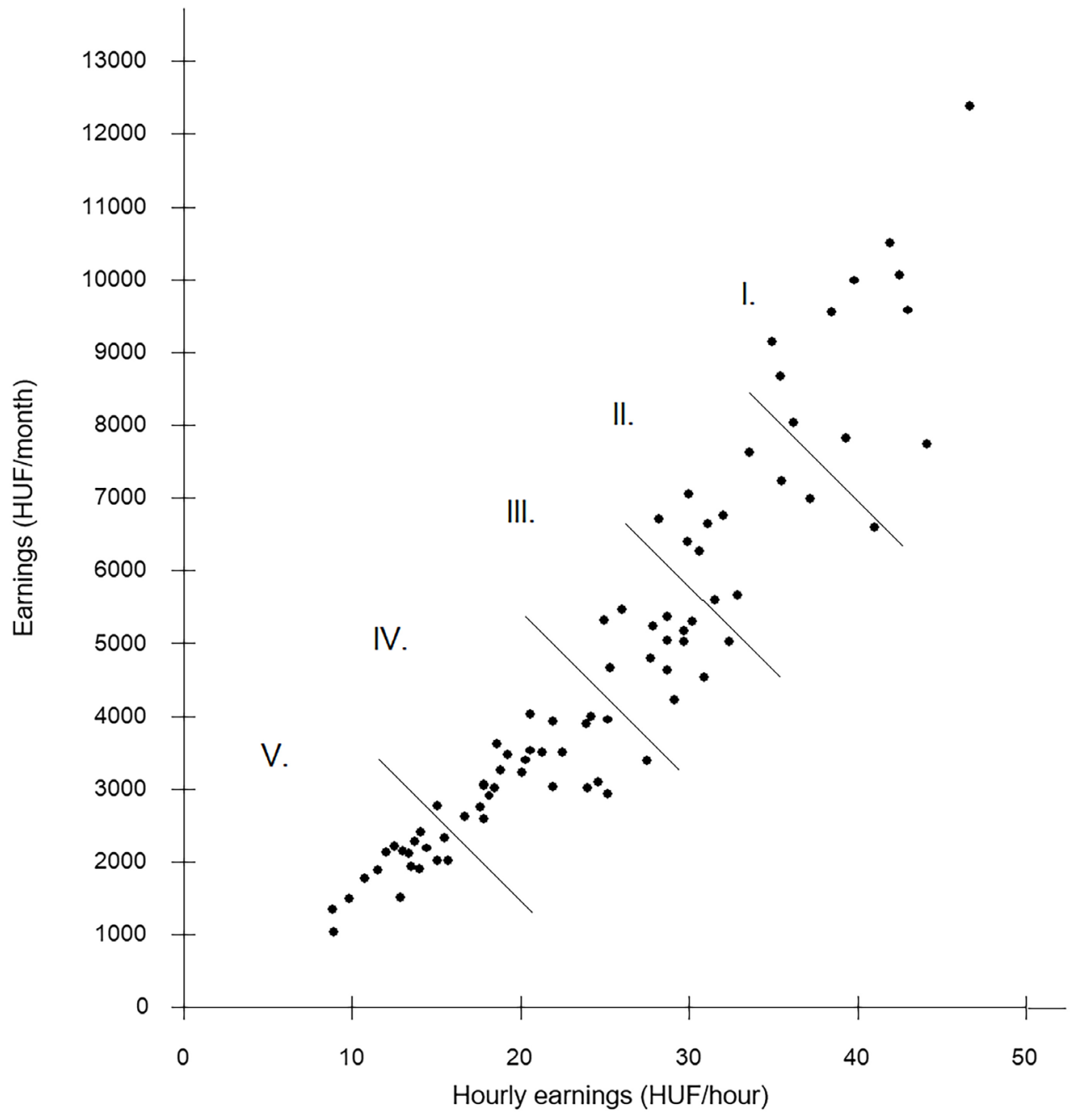

Figure 6. Earnings and hourly earnings on the shop floor

As seen in the theoretical article, by social status we mean the degree of interest realization in the given social group regarding all of the interests of the individual and compared to the 
degree of interest realization of others. In the machining shop floor, the social status of the workers is reflected by the so-called earnings status. The concept of earnings status expresses how much an individual earns and through what amount of expenditure; the more the given individual earns with an expenditure still acceptable for him or her, the more favourable the earnings status is. In the research I classified the workers into five categories according to their earnings status, which is also shown in the above-mentioned figure.

According to the conception discussed in the theoretical article, the degree of interest realization and the social status are basically determined by the social position of the given individual or group. Table 4 shows the distribution of the workers in different social positions according to social (earnings) status; we could even say that this table shows the connection between social structure and social status stratification (see about this: FARKAS 2019. 18-20.). Figure 7, however, shows the average earnings statuses depending on social positions or the social structure. Accordingly, there is a rather tight connection between social position and social (earnings) status.

\begin{tabular}{|l|c|c|c|c|c|c|}
\hline \multirow{2}{*}{\begin{tabular}{c}
\multirow{2}{*}{ Social } \\
position
\end{tabular}} & \multicolumn{5}{|c|}{ Social (earnings) status } & \multirow{2}{*}{ Total } \\
\cline { 2 - 6 } & $\begin{array}{c}\text { Very } \\
\text { good }\end{array}$ & $\begin{array}{c}\text { Relatively } \\
\text { good }\end{array}$ & Medium & $\begin{array}{c}\text { Relatively } \\
\text { bad }\end{array}$ & $\begin{array}{c}\text { Very } \\
\text { bad }\end{array}$ & \\
\hline $\begin{array}{l}\text { Authority } \\
\text { position }\end{array}$ & 6 & 1 & - & - & - & 7 \\
\hline $\begin{array}{l}\text { Strong tolerated } \\
\text { position }\end{array}$ & 3 & 5 & 5 & - & - & $\mathbf{1 3}$ \\
\hline $\begin{array}{l}\text { Supported } \\
\text { position }\end{array}$ & 2 & 4 & 2 & - & - & $\mathbf{8}$ \\
\hline $\begin{array}{l}\text { Medial tolerated } \\
\text { position }\end{array}$ & - & 2 & 6 & 3 & - & $\mathbf{1 1}$ \\
\hline $\begin{array}{l}\text { Patronized } \\
\text { position }\end{array}$ & - & - & - & 12 & - & $\mathbf{1 2}$ \\
\hline $\begin{array}{l}\text { Restricted } \\
\text { position }\end{array}$ & - & - & - & 3 & 1 & $\mathbf{4}$ \\
\hline $\begin{array}{l}\text { Weak tolerated } \\
\text { position }\end{array}$ & - & - & 1 & 4 & 3 & $\mathbf{8}$ \\
\hline $\begin{array}{l}\text { Exposed } \\
\text { position }\end{array}$ & $\mathbf{1 1}$ & $\mathbf{1 2}$ & $\mathbf{1 4}$ & $\mathbf{2 5}$ & $\mathbf{1 8}$ & $\mathbf{8 0}$ \\
\hline Total & - & - & 3 & 14 & $\mathbf{1 7}$ \\
\hline
\end{tabular}

Table 4. Connection between social position and social status on the shop floor

With the exception of one worker, the workers in the authority position have achieved a very good earnings status, that is, they earn a lot of money with an acceptable amount of work. The earnings status of the workers in the authority position is 4.86 on average on a scale ranging from 0 to 5 . The workers in the strong tolerated and supported positions have a relatively good average earnings status (3.85 and 4). According to their earnings statuses, these workers are relatively differentiated, and from a theoretical point of view it was slightly expectable that five 
of them would be in a very good earnings status. However, we will see below that, among the workers in question, the workers who can compensate their lower personal wages (compared to the wages of those in the authority position) with a large volume of additional work in the economic work partnership typically gain a very good earnings status (four out of five men). The workers in the medial tolerated position have an average medium social status (2.91) and are mostly in medium status (6 men). However, such workers can also be found in relatively good and relatively bad earnings statuses ( 2 and 3 men). On the shop floor in question, all of the workers in the patronized position have a relatively bad (2) earnings status. This lags behind what we could generally conclude from the theoretical model, but is better than the status of the other workers having similar (corrected general) powers, especially compared to the status of those in the exposed position. The above-mentioned figure shows that the earnings status of the workers in the restricted position and of those in the weak tolerated position is equally 1.75 on average. Those in the restricted position are typically in a relatively bad status, the earnings status of those in the weak tolerated position is more differentiated; the latter workers are typically divided between the relatively bad and the very bad earnings statuses. The workers in the exposed position have a very bad earnings status, their status is 1.18 on average. Three out of 17 workers have a relatively bad, 14 workers have a very bad earnings status.

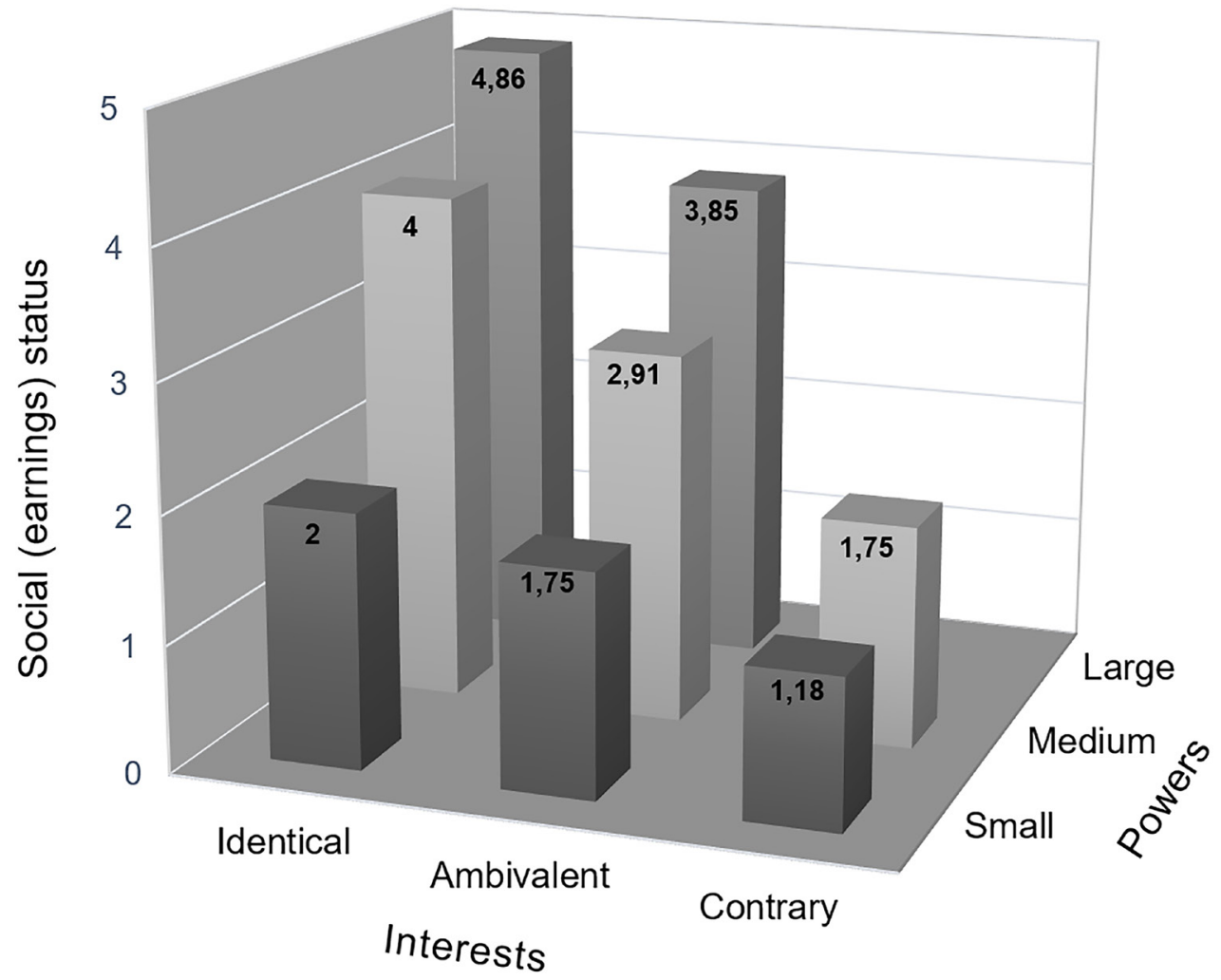

Figure 7. Connection between social position and social status on the shop floor 
In the following few paragraphs, I try to find the answer to the question of to what extent social position (and social stratum position), as well as the two components of social position positions according to power relations and interest relations - determine social (earnings) status. Table 5 shows the correlation coefficients between social status as a determined phenomenon and its determining factors.

\begin{tabular}{|c|c|c|c|c|}
\hline \multirow{2}{*}{$\begin{array}{c}\text { Determined } \\
\text { phenomenon }\end{array}$} & \multicolumn{4}{|c|}{ Determining factors } \\
\cline { 2 - 5 } & $\begin{array}{c}\text { Social } \\
\text { position }\end{array}$ & $\begin{array}{c}\text { Social } \\
\text { stratum } \\
\text { position }\end{array}$ & $\begin{array}{c}\text { Position } \\
\text { by power } \\
\text { relations }\end{array}$ & $\begin{array}{c}\text { Position } \\
\text { by interest } \\
\text { relations }\end{array}$ \\
\hline $\begin{array}{c}\text { Social (earnings) } \\
\text { status }\end{array}$ & 0.91 & 0.91 & $\begin{array}{c}(0.82) \\
0.72\end{array}$ & $\begin{array}{c}(0.58) \\
0.46\end{array}$ \\
\hline
\end{tabular}

Table 5. Correlation of social status with its determining factors

Although I otherwise do not deal with the social stratum position, here I also point out the correlation between stratum position and social status. The correlations of social position and social stratum position with the social (earnings) status are equally 0.91. As mentioned above, compared to social position, social stratum position should, in principle, explain social status to a larger extent. However, whereas, according to their social position, I classified the workers into eight social classes, I only distinguished four social stratum positions. Thus, it is probably the rougher classification by stratum position which explains that social position is in similarly close connection with social status than social stratum position.

As seen in the theoretical article, we make a distinction between two components of social position: the position according to social power relations and the position according to interest relations. When calculating the correlation, I considered the three categories distinguished above for each of these two factors and I ranked these categories according to inequalities. In the given cells of the above-mentioned table we can see the simple correlation coefficients in brackets, and below, the partial correlation coefficients.

In my conception, the two above-mentioned components of social position determine the degree of interest realization and the social status in connection with each other. The correlation between the positions according to power relations and the positions according to interest relations is 0.25 , (not shown in the table). The correlation coefficient between the positions according to social power relations and social (earnings) statuses is 0.82 ; between the positions according to interest relations and social (earnings) statuses it is 0.58 . Independently of the effect of the other factor (positions according to power relations or interest relations), the partial correlation coefficient between the positions according to power relations and social (earnings) statuses is 0.72 ; the partial correlation coefficient between the positions according to interest relations and social (earnings) statuses is 0.46 . Accordingly, social power relations determine the social (earnings) status to a more significant degree than interest relations, however, the effect of interest relations is also significant. In connection with each other, the two factors, that is, the social position determines the social (earnings) status in 83 percent, that is, how much the worker earns by what expenditure. 


\section{Distribution of the degree of interest realization}

In the research in question, I analysed the distribution of the degree of interest realization regarding the different components of earnings interests in very detail. Accordingly, the social position of the worker basically determines to what extent he or she realizes his/her interests with special regard to (1) direct wage factors (personal wage, performance percentage and additional work), (2) supply of work tasks, workpieces and means of work, (3) shift number and shift rota, as well as (4) direct work. However, given the size constraints of this article, in the following I only point out to what extent the workers in different social positions realize their interests concerning earnings, performance percentages and the so-called performance possibilities.

We could see above that the earnings of the workers were very unequal; the difference between the lowest and the highest earnings is nearly tenfold and the difference between the earnings of the workers in very bad earnings status and in very good earnings status is nearly fivefold (1940 and 9410 HUF). However, the question may arise whether the interest of the workers really aims at achieving the highest possible earnings and hourly earnings up to a certain limit. I dealt with this issue relatively in detail elsewhere and I pointed out that the higher earnings statuses and the expenditures belonging to them usually correspond to the interests of the workers more than lower earnings statuses and the expenditures belonging to them (FARKAS 2011. $10-14$.$) .$

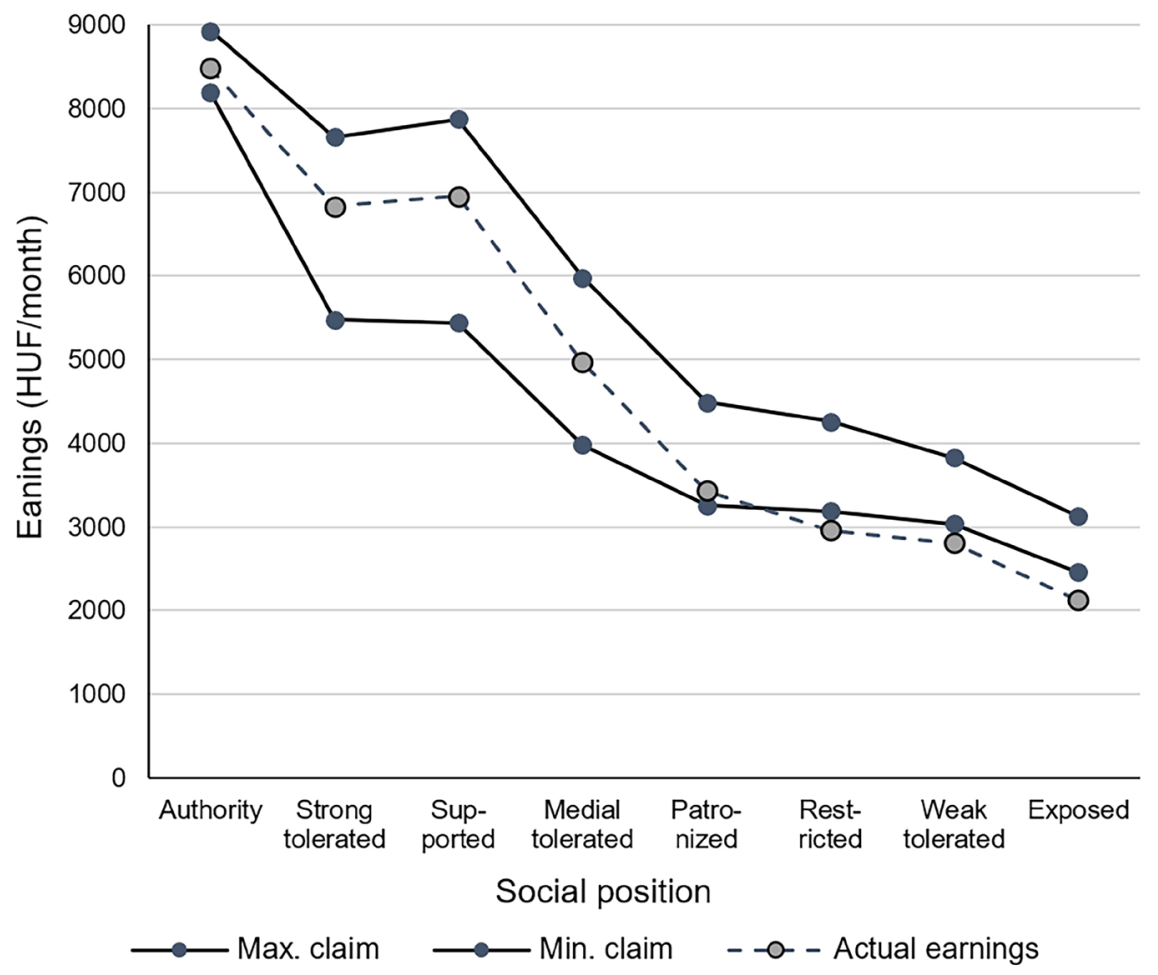

Figure 8. Claims concerning earnings and the actual earnings 
In order to answer the question mentioned above, I also surveyed the claims of the workers concerning the interest components aiming at the wage factors. According to my assumption, namely, the claims largely reflect certain components of earnings interests. We have to see, however, that the claims usually reflect feasible interests, the part of the interests the worker is able to realize, rather than the whole of the interests. The individual takes into consideration to what extent he or she can realize his/her interests and formulates his/her minimum and maximum claims concerning the particular interest components (earnings, personal wage, performance percentage, etc.) mainly in proportion to this. Besides, the workers develop their ideas concerning a just or equitable payment, which, to a certain extent, also influences their claims.

To survey the claims concerning earnings and the components of earnings is, methodologically, not free of problems. It is especially the workers with a very good earnings status that conceal their actual earnings status and ambitions; therefore either they do not usually reveal their actual claims, or they try to obscure them with different ideologies, since they are afraid that the information they might give could serve as a basis for arrangements that could have an unfavourable effect on their interests or their possibilities of interest realization. In view of this, in the research I surveyed the claims regarding earnings and the components of earnings with several questions in an indirect way and I combined the answers with the data in the official wage registration (which I had already been familiar with when interviewing the workers). ${ }^{11}$

In Figure 8 we can see the actual earnings and the minimum and maximum claims concerning earnings, in connection with social position. In accordance with the above-mentioned statements, the claims of workers are not usually aimed at achieving the highest earnings corresponding to earnings interests; the claims largely conform to the status available for the given worker, i.e. his or her feasible interests. According to the figure, the claims of the workers in the authority position, then the workers in strong tolerated and in the supported position are the highest, and the earnings they are paid (8480, 6830 and $6950 \mathrm{HUF} / \mathrm{month})$ are in line with their claims. The claims of the workers in the medial tolerated and the patronized position, orienting to their feasible interests, are comparatively lower, and they usually also achieve the earnings

11 As an example, I present the questions aimed to reveal the maximum and minimum claims concerning performance percentage. As mentioned before, the indirect questions below are necessary because most of the workers would not give a sincere answer to direct questions, although they have clear ideas about them.

1. How satisfied are you with the average performance percentage you have achieved this year (in 1983)? (Answers: on a scale from 1 to 5)

2. I am not asking the actual figure; the important thing about this question is how the workers value the average performance percentage they have achieved this year. Would you have claimed a higher average performance percentage than this if you had had more favorable opportunities to realize your efforts? (Two options: yes or no. If not, go on to question 6.)

3. If you would, by what percentage the maximum would you have liked to raise the performance percentage you have achieved? What is the highest percentage you would have claimed more? (Numerical answer expected.)

4. This year, have you achieved the lowest average performance percentage that you claimed by all means? (Two options: he or she has achieved, or he or she has not achieved it. If he or she has, go on to question 6.)

5. If you have not, approximately what percentage was missing on average for you to achieve the minimum performance percentage you claimed? (Numerical answer. Go on to the question after question 6.)

6. So, you have achieved the minimum performance percentage that you claimed by all means. By what percentage have you exceeded this minimum average percentage this year? (Numerical answer.)

In fact, the average performance percentage of the given worker is known from the wage registration, I already knew it at the time of the interview. From this, and from the answers he or she gave to the questions above, the maximum and minimum claims of the worker can be calculated. 
(4970 and $3430 \mathrm{HUF} / \mathrm{month}$ ) that correspond to their claims. The claims of the workers in restricted, weak tolerated and, especially, in the exposed positions are the lowest, but, typically, these workers cannot even achieve the earnings that correspond to their minimum claims (their actual earnings are 2960, 2810 and 2130 HUF/month).

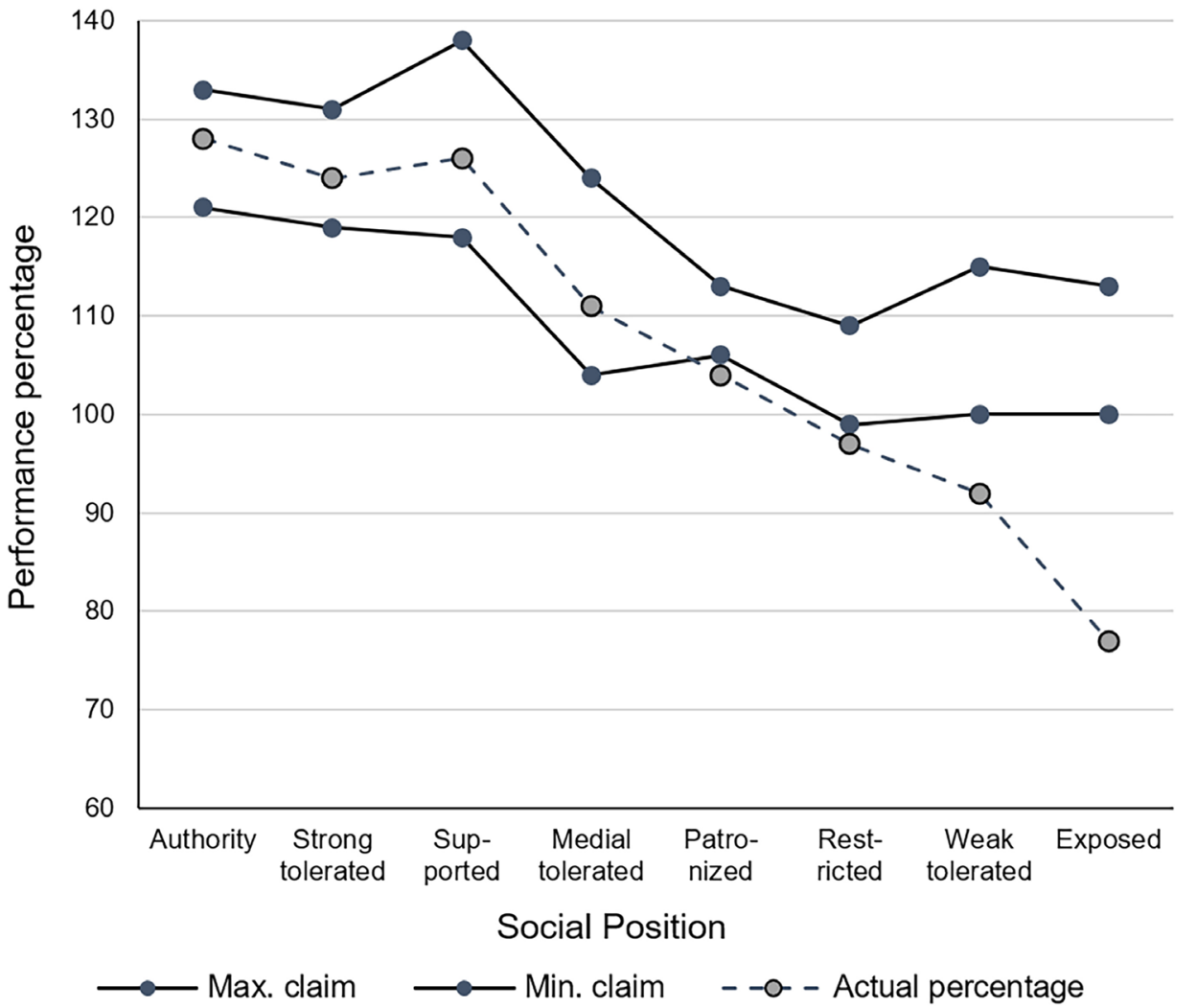

Figure 9. Claims regarding performance percentage and the actual performance percentages

Figure 9 shows actual performance percentages and the minimum and maximum claims concerning performance percentages, in connection with social position. As pointed out elsewhere, higher performance percentages require more expenditure from the individual on the one hand, and, above a certain threshold, due to the norm cutting to be expected, they jeopardize the efficiency of the future expenditure of the worker, on the other (FARKAS 2011. 18-19.). Therefore, a specified performance percentage, which can be regarded as optimum according to the above aspects and from the point of view of the earnings, is in line with the interest of the workers. The surveyed claims mostly reflect the feasible interests concerning performance percentages as well, because they indicate the ambitions of the workers in their given social position. However, the claims clearly show that achieving the comparatively high performance 
percentage, or increasing the lower performance percentage, up to a limit of nearly 140 percent (the highest), are in line with the interest of the workers in so far as we take as a basis, on the shop floor under review, the expenditures generally necessary for the workers to achieve the different performance percentages.

The minimum claims of the workers in the authority, strong tolerated and supported positions are around 120 percent; their maximum claims are between 131 and 138 percent. As for the averages, their actual performance percentages can be regarded as optimum for them: it is 128 percent in the authority position, 124 and 126 percent in the strong tolerated and supported positions. The workers in question on occasion could also achieve higher performance percentages but, in the case of the particular tasks, the more they approach 140 percent, the riskier they may think it is. It is the maximum claim of the workers in the supported position that approaches 140 percent the most. To exceed this value would already be very risky for the workers. The minimum and maximum claims of the workers in the medial tolerated position are relatively lower (104 and 124\%), and their actual performance percentage (111\%) exceeds their minimum claims significantly. Those in the patronized position claim minimum 106 and maximum 113 percent and their actual performance percentage (104\%) is only a little lower than their minimum claims. The minimum claim of the workers in the restricted, weak tolerated and exposed positions is around 100 percent. The actual performance percentage of the workers in the restricted position is only a little lower than this $(97 \%)$, but the percentage of those in the weak tolerated position $(92 \%)$ lags considerably behind. The status of the workers in the exposed position is, from this point of view, especially bad; with their 77 percent performance on average, they lag behind the claimed minimum of 100 percent to a large extent.

As seen above, the most important components of interests are made up of the components regarding the supply of tasks, workpieces and means of work. Unsatisfactory supply may greatly hinder the worker in achieving the performance percentage appropriate to his or her expertise and effort, but in connection with this, also in doing the amount of additional work that corresponds to his or her interest. In the course of the research I surveyed the main problems and the inequalities of the degree of interest realization in this regard in detail, but here I will only point out the inequalities in question between the different social classes very briefly.

By performance possibility status I mean the status of the worker from the point of view of the extent to which he or she is supplied with work tasks, workpieces and means of work in line with his or her interest. I measured the performance possibility status of the workers on a scale from 1 (the worst) to 5 (the best), and I took into consideration to what extent the given worker is hindered in achieving the performance percentage in compliance with his or her expertise and effort (and in connection with this, doing the amount of additional work in line with his or her interest) by the following factors: (1) shortage of work and/or shortage of material, (2) tasks with short piece time and/or few pieces, tasks only enough for a short period of time, (3) work norms that are stricter than the average and more difficult to perform, (4) the bad state or malfunction of the machine and (5) lack or unsuitable quality of special device. 


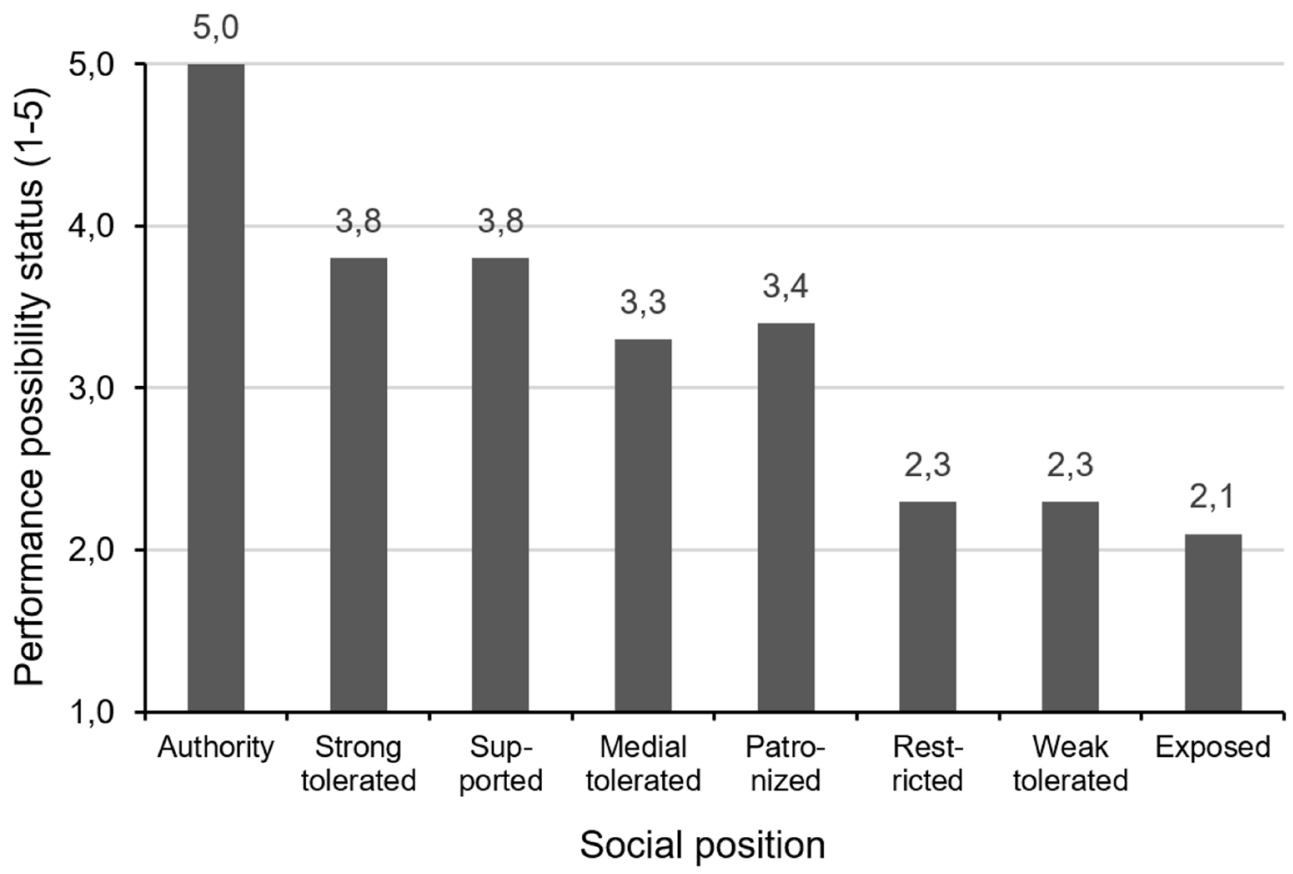

Figure 10. Connection between social position and performance possibility status

Figure 10 shows the average performance possibility status of the workers in different social positions. Accordingly, the workers in the authority position are all in a very good performance possibility status, their average status is 5 . Next, those in the strong tolerated and supported positions are in relatively the best performance possibility status with an average status of 3.8 . The status of the workers in the medial tolerated and patronized positions is, from this point of view, very similar; the status of the former is 3.3, that of the latter is 3.4. The average status of the workers in the restricted and weak tolerated positions is, equally, 2,3. The performance possibility status of the workers in the exposed position is the worst; they are in a status of an average 2.1. Accordingly, insufficient supply of work tasks, workpieces and means of work largely hinder the workers in restricted, weak tolerated and exposed social position in achieving the performance percentage appropriate to their expertise and effort and, in connection with this, in doing the amount of additional work in line with their interest.

\section{Social position and performance orientations}

Social position determines the social status of the given individual or group in connection with the determination of their social conduct. Below, I highlight the social conduct of the workers as well as the determinedness of their conduct by social position with regard to the so-called performance orientation.

Although, as mentioned above, I do not analyse the degree of interest realization concerning 
additional work, here we take into consideration the differences in doing additional work from a certain point of view. Namely, it is advisable to analyse performance percentage and additional work in connection with each other, since, as a matter of fact, they jointly express in what period of time, how much recognized performance the workers achieve. Compared to the performance that can be achieved in normal working hours (that is, eight hours a day) and with a normal performance percentage (that is, of around 100 percent), the workers may increase their recognized performance by increasing their performance percentage, on the one hand, and by extending the working hours, i.e. by doing additional work, on the other. By performance orientation I mean the ambition to increase the recognized performances that means a choice from the point of view to what extent the worker seeks to increase his or her recognized performance by increasing his or her performance percentage and/or by extending the working hours.

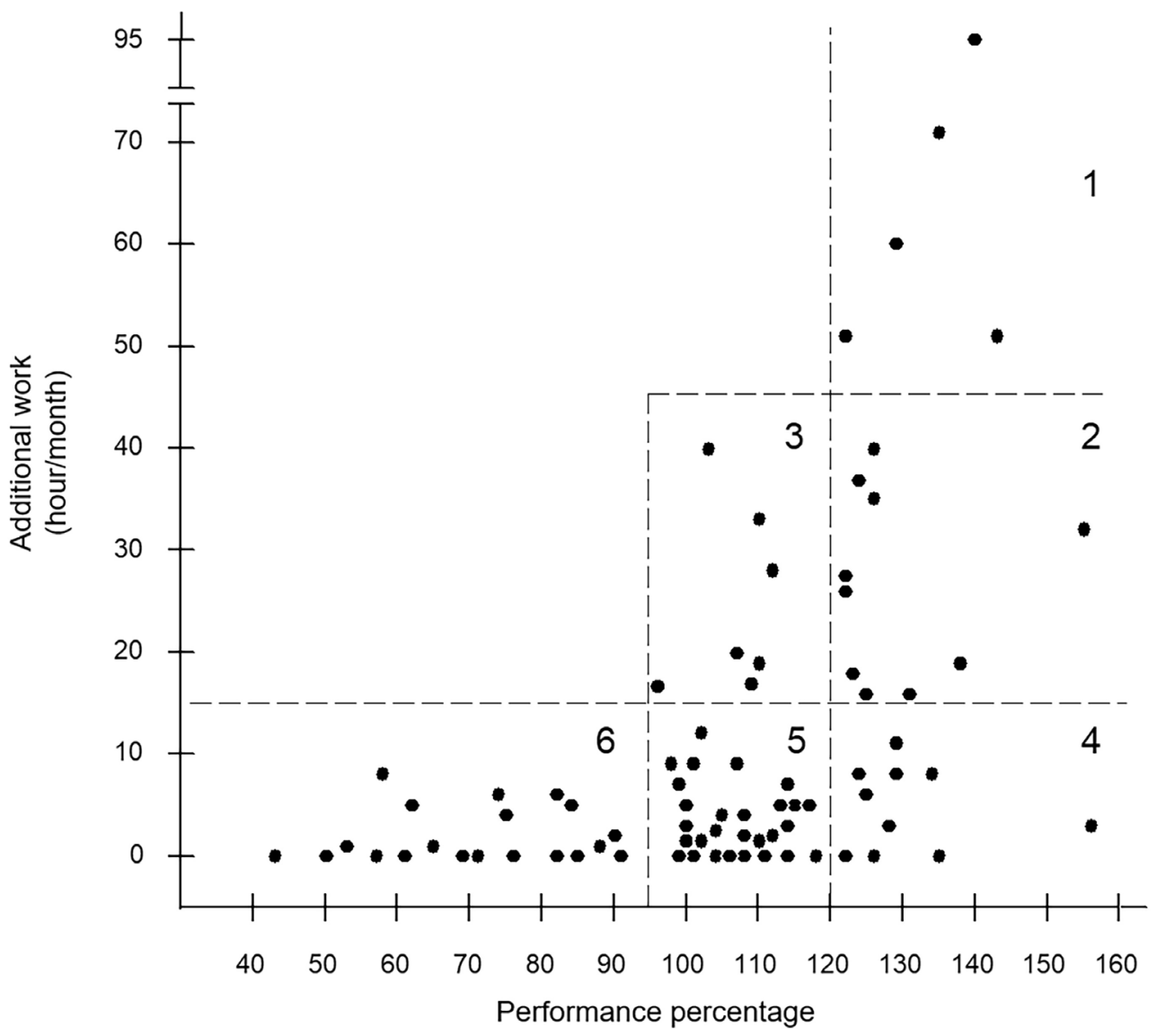

Figure 11. Performance percentages and additional work hours of the workers 
Figure 11 shows the distribution of the performance percentages and monthly additional work hours of the workers in the year 1983, based on the wage registration of the company. Assuming the above-mentioned orientation, I distinguish the following types of performance orientation in the given figure: (1) extra-fulfilment-oriented with GMK, 5 men; (2) overfulfilment- and additional-work-oriented, 10 men, (3) additional-work-oriented, 7 men; (4) overfulfilment-oriented, 10 men; (5) achieving standard performance, $28 \mathrm{men}$; (6) achieving low performance, 20 men.

In the above-mentioned paper, I pointed out that, in connection with personal wage, performance orientation directly determines the earnings status of the worker to a large extent (FARKAS 2011.16-17.). Nevertheless, I also emphasized that a similar earnings status can also be achieved partly by different orientations. As an example, the very good earnings status can also be achieved if the worker is overfulfilment- and additional-work-oriented, and, at the same time, has an outstanding personal wage, but the lack of outstanding personal wage can be made up for by extra fulfilment-orientation.

Table 6 shows the performance orientations more or less typical of the workers in different social positions. Accordingly, the workers in the authority position are typically overfulfilmentand additional-work-oriented ( 5 men), less typically overfulfilment-oriented ( 2 men). Besides, these workers have outstanding personal wage (27.6 HUF/hour), and in this way achieve a very good (6 men) or, possibly, a relatively good (1 man) earnings status. If they intended to, they could also join the economic work partnership within the shop floor or they could also set up another work partnership, within which they could do an outstanding amount of additional work, but, being paid high personal wage, they do not need to do so.

\begin{tabular}{|l|c|c|c|c|c|c|c|}
\hline \multirow{2}{*}{\begin{tabular}{c}
\multirow{2}{*}{$\begin{array}{c}\text { Social } \\
\text { position }\end{array}$} \\
\cline { 2 - 8 }
\end{tabular}} & $\begin{array}{c}\text { Extra-fulfil- } \\
\text { ment with } \\
\text { GMK }\end{array}$ & $\begin{array}{c}\text { Overfulfil- } \\
\text { ment- and } \\
\text { add. work }\end{array}$ & $\begin{array}{c}\text { Overfulfil- } \\
\text { ment }\end{array}$ & $\begin{array}{c}\text { Additional } \\
\text { work }\end{array}$ & $\begin{array}{c}\text { Standard } \\
\text { fulfilment }\end{array}$ & $\begin{array}{c}\text { Under- } \\
\text { fulfilment }\end{array}$ & Total \\
\hline $\begin{array}{l}\text { Authority } \\
\text { position }\end{array}$ & - & 5 & 2 & - & - & - & 7 \\
\hline $\begin{array}{l}\text { Strong tolerated } \\
\text { position }\end{array}$ & 3 & 2 & 3 & 2 & 3 & - & $\mathbf{1 3}$ \\
\hline $\begin{array}{l}\text { Supported } \\
\text { position }\end{array}$ & 2 & 1 & 3 & 2 & - & - & $\mathbf{8}$ \\
\hline $\begin{array}{l}\text { Medial tolerated } \\
\text { position }\end{array}$ & - & 2 & 1 & 3 & 5 & - & $\mathbf{1 1}$ \\
\hline $\begin{array}{l}\text { Patronized } \\
\text { position }\end{array}$ & - & - & - & - & 12 & - & $\mathbf{1 2}$ \\
\hline $\begin{array}{l}\text { Restricted } \\
\text { position }\end{array}$ & - & - & - & - & 2 & 2 & 4 \\
\hline $\begin{array}{l}\text { Weak tolerated } \\
\text { position }\end{array}$ & - & - & - & - & 4 & 4 & $\mathbf{8}$ \\
\hline $\begin{array}{l}\text { Exposed } \\
\text { position }\end{array}$ & $\mathbf{5}$ & $\mathbf{1 0}$ & $\mathbf{1 0}$ & $\mathbf{7}$ & $\mathbf{2 8}$ & $\mathbf{2 0}$ & $\mathbf{8 0}$ \\
\hline Total & - & 1 & - & 2 & 14 \\
\hline
\end{tabular}

Table 6. Connection between social position and performance orientation 
The performance orientation of the workers in the strong tolerated and supported positions is rather differentiated. A relatively good or medium social status is typical of the workers in question, and they have mostly achieved it by overfulfilment and/or additional work ( 7 men and 6 men). However, some of them (3 men), have only achieved standard performance. The members of the economic work partnership ( 6 men) emerge out of the workers in the strong tolerated and supported positions; 5 of them ( 3 men from the strong tolerated position and 2 men from the supported position) are oriented to extra-fulfilment, i.e. overfulfilment and an outstanding amount of additional work in the frame of the economic work partnership; one worker (from the strong tolerated position), however, is only oriented to a moderate amount of additional work. Thus, some of the workers in a less advantageous position than the authority position, seek to achieve a good social (earnings) status, similar to that of the workers in the authority position, by expanding their working hours considerably. As mentioned above, those of the workers in the strong tolerated and supported positions that can compensate their (compared to those in the authority position) lower personal wages (23.0 and 22.7 HUF/hour) by doing an outstanding amount of additional work in the economic work partnership can typically achieve a very good social (earnings) status.

The workers in the medial tolerated position mostly achieve standard performance ( 5 men), and some of them are able to increase their recognized performance with overtime ( 3 men), or with overtime and overfulfilment ( 2 men), rather than with only overfulfilment (1 man). All of the workers in the patronized position (12 men) achieve standard performance. The performance orientation of the members of the restricted social class and the weak tolerated class are proportionally similar; one half of the workers achieve standard performance, whereas relative underperformance is typical of the other half. In the above analysis of the degree of interest realization from the point of view of performance percentage, we could also see that, with their average 77 percent performance, the workers in the exposed position considerably lag behind the standard performance. The workers in question (14 out of 17 men) typically achieve low recognized performance.

\section{SUMMARY}

In this paper, I illustrated the institutional (and relational) sociological conception of social position and social status by a brief description of a case study. I analysed the social positions and the social statuses of the workers, as well as the determinedness of social statuses by the given social positions on a machine industrial shop floor.

First, I outlined the interests and social powers of the workers. Accordingly, the components of interests on the given shop floor can be interpreted at three levels. The first level includes the general feature of the earnings interest that the earnings interest is made up of the action possibilities of optimizing the earnings and expenditures. The second level includes the components concerning wage factors. At this level, the interests of the workers are mainly made up of the maximization of their personal wage, and the optimization of their performance percentage and their additional work. The third level of the components of interests includes the components concerning means of work, work tasks and doing work. The main components of interests at 
this level are as follows: optimization of the supply with means of work, optimization of work supply and, in connection with this, loosening of norm times; and in close connection with the former issues, the optimization of the number of shifts and the optimization of direct work.

In the given research, I measured the intensity of the social powers of workers towards the shop floor managers and towards all the workers on the shop floor by asking two questions. I determined the average powers of the workers towards their fellow-workers, and then I classified the workers according to their powers towards the managers on the one hand, and according to the intensity of their average powers towards their fellow-workers on two separate scales ranging from one to five (from small powers to large powers).

The research results in part supported my hypothesis that the components of the social powers of the workers are mainly made up of the following social abilities: (1) scope of action at work, (2) expertise, (3) scope of action in the party or the trade union, (4) social relationship and (5) quasi-ownership on the shop floor. In this respect, I dealt with the powers towards the managers in more detail, because these powers are more significant from the point of view of the extent to which the workers realize their interests, and what social status they achieve.

It is mainly expertise (and effort) and the quasi-ownership within the shop floor, by themselves and independently of other social abilities, that constitute the social powers towards the managers. Compared with these abilities, directly, the scope of action at work has a much smaller significance, but, in the longer term, the scope of action at work also affects other social abilities. Independently of other social abilities, the scope of action in party or trade union and social relationships have a rather small significance. The social abilities in question constitute 81 percent of the social powers of the workers towards the managers. However, the social abilities under review amount only to nearly 58 percent of the powers towards the workers.

Then, I mapped the social positions of the workers, that is, I outlined the social structure of the shop floor. One aspect of typifying is, in principle, the social power relations with those in an authority position. However, during the empirical survey of the social position of workers, to a certain extent, I also took their power relations to other individuals with relatively significant powers into consideration. Taking the powers towards the managers and the average powers towards the workers with the same weight into consideration, I determined the general powers of the particular workers. However, I corrected the general powers from the point of view of mapping social positions, and outlining the social structure, attributing greater importance to the powers towards the managers. Finally, according to their corrected general powers, I placed the workers into three categories. In this way, 20 workers $(25 \%)$ have large corrected general power, 23 workers $(29 \%)$ have medium power and 37 workers $(46 \%)$ have small power.

In principle, the other aspect of typifying is constituted by the interest relations to those having authority. However, during the empirical research, to a certain extent, I also took interest relations to other individuals with relatively significant powers into consideration. I defined the interest relations within the shop floor in the following three ways, regarding the managers on the one hand, and the fellow-workers on the other: (1) I surveyed the social relationships within the shop floor; (2) I attempted to survey the interest relations between the workers and the managers partly with a question that I asked the head of shop floor and two foremen; (3) I determined the interest relations between the workers partly by considering the interconnection or separation of means of work, work tasks and work accounts. 
Thus, in line with the above-mentioned criteria, I classified the workers into the different social positions and the different social classes according to the social power relations and interest relations. Accordingly, 7 workers (nearly 9\%) are in authority position, i.e. they constitute the authority class, along with four managers composing the core of the management. 13 workers (nearly 16\%) are in strong tolerated position and they constitute the strong tolerated class. Among the workers with medium social power, 8 workers (10\%) are in supported position and in the supported class; 11 workers (nearly 14\%) are in medial tolerated position and 4 workers $(5 \%)$ are in restricted position and they constitute the medial tolerated class and the restricted class. Among the workers with small social power, 12 workers (15\%) are in patronized position and they constitute the patronized class, 8 workers $(10 \%)$ are in weak tolerated position and constitute the weak tolerated class, and 17 workers (nearly $21 \%$ ) are in exposed position and constitute the exposed class.

Then I dealt with the social statuses and the social determinedness of social statuses, and finally, I briefly touched upon the performance orientations of the workers. I pointed out that the social status of the workers is well reflected by the so-called earnings status. I intended to find the answer mainly to the question of to what extent social position, as well as the two components of social position - positions according to power relations and interest relations - determine social (earnings) status. According to the research results, there is a rather tight connection between social position and social (earnings) status. Social power relations determine the social (earnings) status to a more significant degree than interest relations, however, the effect of interest relations is also significant. In connection with each other, the two factors, that is, the social position determines the social (earnings) status in 83 percent, that is, how much the worker earns by what expenditure.

In the research in question, I analysed the distribution of the degree of interest realization regarding the different components of earnings interests in very detail. However, in this paper, I only pointed out to what extent the workers in different social positions realize their interests concerning earnings, performance percentages and the so-called performance possibilities. According to this, the social position of a worker basically determines the extent to which he or she realizes his or her interest in the mentioned aspects. Social position determines the social status of the given individual or group in connection with the determination of their social conduct. In this paper, I highlighted the social conduct of the workers as well as the determinedness of their conduct by social position with regard to the so-called performance orientation.

\section{REFERENCES}

Barnes, Barry (1988): The Nature of Power. Cambridge, UK, Polity Press.

Burawoy, Michael - Lukács János (1992): The Radiant Past. Ideology and Reality in Hungary's Road to Capitalism. Chicago, The University of Chicago Press.

D’Antonio, William V. - Eugene C. Erickson (1962): The Reputational Technique as a Measure of Community Power: An Evaluation Based on Comparative and Longitudinal Studies. American Sociological Review Vol. 27. No. 3. 362-376. https://doi.org/10.2307/2089798 
FARKAS, ZolTÁn (2011): Az intézmények és az érdekek az üzemben. [Institutions and Interests on a Shop Floor]. Magyar Elektronikus Könyvtár. Available at: https://www.researchgate.net/ publication/315522779

FARKas, Zoltán (2019): Social Structure and Social Stratification: Two Chapters for the Outline of Social Theory. Manuscript in ResearchGate. Available at: https://www.researchgate. net/publication/337103006

Farkas, Zoltán (2020): Social Position and Social Status: An Institutional and Relational Sociological Conception. Manuscript in ResearchGate. Available at: https://www.researchgate. net/publication/337312798

Fischer, Manuel - Pascal Sciarini (2015): Unpacking Reputational Power: Intended and Unintended Determinants of the Assessment of Actors' Power. Social Networks Vol. 42. 60-71. https://doi.org/10.1016/j.socnet.2015.02.008

Goldberg, Avi (2006): Confronting the Absent-Present: Material and Discursive Power in Israeli-Palestinian Political Alliances. Berkeley Journal of Sociology: A Critical Review Vol. 50. 3-36.

Haraszti, Miklós (1977): A Worker in a Worker's State: Piece-Rates in Hungary. New York, Penguin Books.

Henry, Adam D. (2011): Ideology, Power, and the Structure of Policy Networks. Policy Studies Journal Vol. 39. No. 3. 361-383. https://doi.org/10.1111/j.1541-0072.2011.00413.x

HÉTHY, LAJOS - MAKó, CsABA (1978): Munkások, érdekek, érdekegyeztetés. [Workers, Interests, Interest Reconciliation]. Budapest, Gondolat Kiadó.

Hill, StePhen (1986): Competition and Control at Work. Hampshire, Gower Publishing Company.

Kriesi, Hanspeter - Silke Adam - Margit Jochum (2006): Comparative Analysis of Policy Networks in Western Europe. Journal of European Public Policy Vol. 13. No. 3. 341-361. https://doi.org/10.1080/13501760500528803

Margetts, Helen (2011): Reputational Analysis. In Keith Dowding (ed.): Encyclopedia of Power. Los Angeles, SAGE Publications. 570-571.

Whitmeyer, Josept M. (2001): Measuring Power in Exchange Networks. Sociological Perspectives Vol. 44. No. 2. 141-162. https://doi.org/10.2307/1389608 


\section{Appendix}

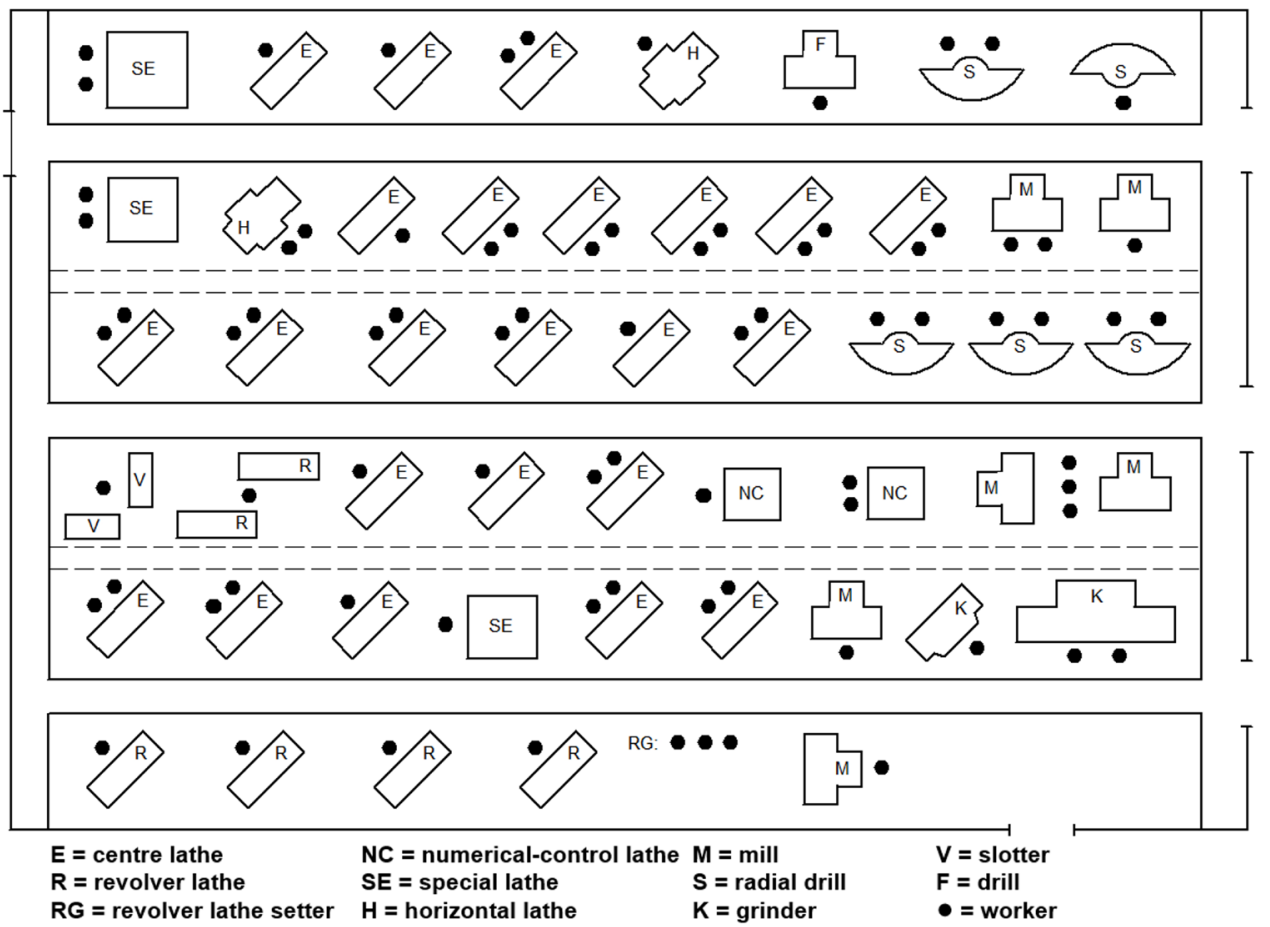

Figure 1. Rough layout of the Machining Shop Floor 


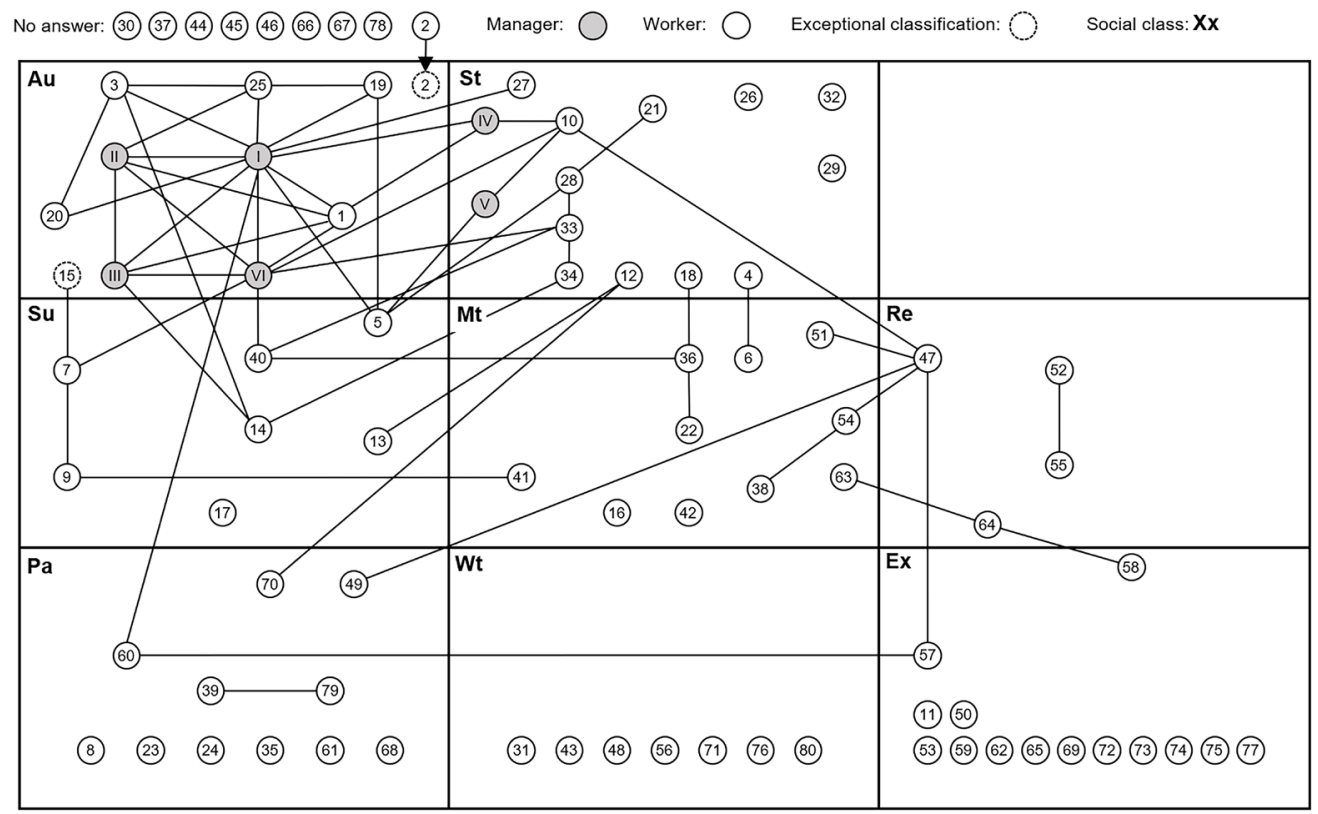

Figure 5. Network diagram: Social relationships (mutual choices) on the Machining Shop

Floor by social classes. (Notation: $\mathrm{Au}=$ Authority class, $\mathrm{St}=$ Strong tolerated class, $\mathrm{Su}=$ Supported class, $\mathrm{Mt}=$ Medial tolerated class, $\mathrm{Pa}=$ Patronized class, $\mathrm{Re}=$ Restricted class, $\mathrm{Wt}$ $=$ Weak tolerated class, Ex $=$ Exposed class) 